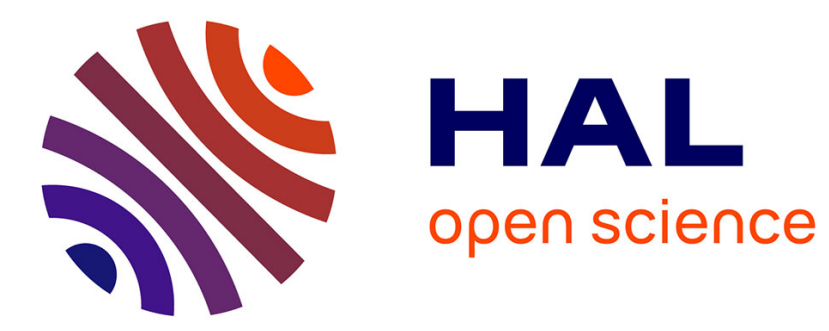

\title{
Parameters uncertainties and error propagation in modified atmosphere packaging modelling
}

Valérie Guillard, Carole Guillaume, Sébastien Destercke

\section{To cite this version:}

Valérie Guillard, Carole Guillaume, Sébastien Destercke. Parameters uncertainties and error propagation in modified atmosphere packaging modelling. Postharvest Biology and Technology, 2012, 67, pp.154-166. 10.1016/j.postharvbio.2011.12.014 . hal-00669378

\section{HAL Id: hal-00669378 https://hal.science/hal-00669378}

Submitted on 13 Feb 2012

HAL is a multi-disciplinary open access archive for the deposit and dissemination of scientific research documents, whether they are published or not. The documents may come from teaching and research institutions in France or abroad, or from public or private research centers.
L'archive ouverte pluridisciplinaire $\mathbf{H A L}$, est destinée au dépôt et à la diffusion de documents scientifiques de niveau recherche, publiés ou non, émanant des établissements d'enseignement et de recherche français ou étrangers, des laboratoires publics ou privés. 


\title{
Parameter uncertainties and error propagation
}

\section{in modified atmosphere packaging modelling}

\author{
V. Guillard ${ }^{1, *}$ C. Guillaume ${ }^{1}$ AND S. Destercke ${ }^{2}$
}

${ }^{1}$ Joint Research Unit Agropolymers Engineering and Emerging Technologies - UMR 1208 Montpellier SupAgro, INRA, UM2, CIRAD - CC023 place Eugène Bataillon 34095 Montpellier cedex 5 - France

${ }^{2}$ Joint Research Unit Heuristic and Diagnosis of Complex Systems - UMR 6599 CNRS

UTC, Centre de recherché de Royallieu, 60205 Compiegne

* corresponding author

\section{Higlights}

- Interval analysis is proposed to study error propagation in MAP modelling for 3 fresh produce

Results are compared to a probabilistic Monte-Carlo approach

Low computational costs to estimate upper and lower $\mathrm{O}_{2}$ and $\mathrm{CO}_{2}$ limits

MAP optimisation generates robust solutions for $\mathrm{O}_{2}$ and $\mathrm{CO}_{2}$ permeabilities, expressed as fuzzy sets

Experimental efforts should focus on produce physiology for better accuracy of prediction 


\begin{abstract}
Mathematical models are instrumental tools to predict gas $\left(\mathrm{O}_{2}\right.$ and $\left.\mathrm{CO}_{2}\right)$ evolution in headspaces of Modified Atmosphere Packaging (MAP). Such models simplify the package design steps as they allow engineers to estimate the optimal values of packaging permeability for maintaining the quality and safety of the packed food. However, these models typically require specifying several input parameter values (such as maximal respiration rates) that are obtained from experimental data and are characterized by high uncertainties due to biological variation. Although treating and modelling this uncertainty is essential to ensure the robustness of designed MAPs, this subject has seldom been considered in the literature. In this work, we describe an optimisation system based on a MAP mathematical model that determines optimal permeabilities of packaging, given certain food parameters. To integrate uncertainties in the model while keeping the optimisation computational burden relatively low, we propose to use an approach based on interval analysis rather than the more classical probabilistic approach. The approach has two advantages: it makes a minimal amount of unverified assumption concerning uncertainties, and it requires only a few evaluations of the model. The results of these uncertainty studies are optimal values of permeabilities described by fuzzy sets. This approach was conducted on three case studies: chicory, mushrooms and blueberry. Sensitivity analysis on input parameters in the model MAP was also performed in order to point out that parameter influences are dependent on the considered fruit or vegetable. A comparison of the interval analysis methodology with the probabilistic one (known as Monte Carlo) was then performed and discussed.
\end{abstract}

\title{
Keywords
}

MAP modelling, fresh fruits and vegetables, interval analysis, sensitivity analysis, biological variability 


\section{Introduction}

The treatment of uncertainties is crucial in food engineering and in mathematical modelling of process units. Indeed, in such mathematical models input parameters are sometimes physical constants or measurable quantities that are exactly known, but more often than not they refer to properties that cannot be directly measured and that are calculated from linear or non-linear (multiple) regressions obtained from experimental data. The accuracy of calculated parameters then depends on the experimental uncertainty. Accuracy of such parameters is crucial, as they are then used in mathematical models to perform simulation or even identification of a third parameter (as is the case here).

Modified atmosphere packaging (MAP) for fresh fruit and vegetables relies on the modification of the atmosphere inside the package in order to extend the food shelf life by reducing the respiration of the product and consequently its degradation rate. Atmosphere composition within the package is the result of both respiration of the commodity and diffusion/permeation of gases through the film until a steady modified atmosphere is reached (Floros and Matsos, 2005). This steady atmosphere must be quickly reached and as close as possible to optimal gas concentrations specific to each product. To do so, gas transfer properties of the packaging must correctly match physiological requirements of the product. In order to design MAP for fresh fruit and vegetables, mathematical models that simulate the evolution of internal gas composition in the packaging as a result of food respiration and mass transfer through the packaging material can be used to identify optimal values of gas permeabilities that will provide maximal shelf life to a given product (Charles et al., 2003; Mahajan et al., 2007). Optimised packaging can then be designed accordingly to these identified values. Examples of such mathematical models are available through webapplication (PackInMap (Mahajan et al., 2007) or www.tailorpack.com). These mathematical models require specifying a lot of input parameters such as film thickness, area, mass of 
packed vegetables, gas permeabilities for the packaging material, etc., and, of course, the respiration characteristics of the product, i.e., at least, the maximal respiration rate (or ) and the apparent Michaelis-Menten constant () necessary to model the physiology of aerobic respiration using a Michaelis-Menten formalism, the most encountered enzymatic kinetic mechanism describing respiration (Fonseca et al., 2002). These parameter values are estimated from experimental data and are characterised by high uncertainties due to the biological variation (Hertog et al., 2004; Hertog et al., 2007a; Hertog et al., 2007b). For instance, a search for available data in the literature concerning the maximal respiration rate of a same variety of mushrooms (Agaricus biporus L.) gives more than five different references that each provide different values of respiration rates and Michaëlis-Menten constant (Table 1). It is obvious from Table 1 that a single value of respiration rate cannot faithfully represent biological variability, even if products come from a unique plot (same climatic exposition, time of harvest, etc.). Also, it would be hazardous to use these data to evaluate a probability distribution, as their heterogeneity is high (different batch, location, labs, etc.). A more reliable model would be to consider a range of possible values reflecting this biological variability. In any case, modelling this variability would increase the reliability of simulations used, for instance, to design MAP for mushrooms.

Although uncertainty treatment is an essential part of robust design, this subject has been seldom considered in food engineering. We can mention Baudrit et al. (2007, 2009) who study the impact of jointly propagating variability and imprecision in models of weight loss during cheese ripening process, Hertog et al. (Hertog et al., 2007b; Hertog et al., 2009) who evaluate the impact of biological variation on vegetables postharvest behaviour (tomato colour or stem length of Belgian endive for example) and Iqbal et al. (2009b) who evaluate the impact of mushroom respiration rate () variability on the concentration of oxygen and 
carbon dioxide in the packaging headspace at equilibrium. All these previous studies mostly use classical probabilistic models (Bedford and Cooke, 2001) with Monte Carlo simulations (in the case of Baudrit et al. (2009), these methods were mixed with imprecise probabilistic models). Such simulations require to (i) know and specify the (possibly imprecise) distribution of each input variable, (ii) specify the dependency structures between all input variables and (iii) perform (computationally costly) numerical analyses to evaluate the output uncertainty. Meeting such requirements necessitates a great amount of information and data as well as lengthy computational time. When not enough information is available (a situation that often happens), distribution shapes (e.g., normality) and dependence assumptions (e.g., independence between all variables) are usually chosen accordingly to some purely practical criterion. The validity of such choices, if not confirmed by experiments or available knowledge, may be questioned as well as the validity of subsequent analysis results (Ferson and Ginzburg, 1996). Indeed, they may provide misleading conclusions, which may in some cases lead to unwarranted and non-robust design choices.

When few data are available, an alternative is to use interval analysis (Jaulin et al., 2001) to perform the uncertainty analysis. It comes down to considering that only the bounds in which each input variable and parameter may vary are known, or in other words, that (i) input variable distributions are unknown (up to their bounds) and (ii) the dependence structure between input variables is unknown. Compared to probabilistic analysis, interval analysis can therefore be seen as a conservative analysis, in the sense that it does not make any additional hypothesis with regard to the available information, and possibly ignores some of the available information. It will therefore provide more robust, but less informative, conclusions than probabilistic analysis.

Actually, interval and probabilistic analysis can be seen as two extreme methods of uncertainty treatment: the former relies on very few assumptions and provides robust yet 
poorly informative results, in the sense that only bounds are provided, while the latter requires a lot of information but provides very informative results (e.g., in the shape of confidence intervals, frequencies) whose reliability is nevertheless questionable if information is missing and hypotheses have to be made. Most practical situations are situated between these two extremes and the choice between the two methods often depends of the application goals.

In this paper, we use interval analysis to study the impact of parameter uncertainties in a MAP model describing the gas composition evolution inside the package, and presented in Section 2. We propose in Section 3 a method relying on interval analysis to perform uncertainty analysis (propagation and sensitivity analysis) and to determine (in a reverse optimisation step) optimal values of packaging oxygen and carbon dioxide permeabilities. This approach is tested in Section 4 on three case studies covering various scenarios: chicory, mushrooms and blueberry. Indeed, they span high (mushrooms) and low (endive and blueberry) respiration rates, important $\mathrm{CO}_{2}$ inhibition (blueberries) or not (mushrooms and chicory), great $\mathrm{O}_{2}$ sensitivity (chicory) or not (mushrooms and blueberry). Collected information also presents significant differences: higher (mushrooms and blueberry) and lower variability (chicory), data from a single reference (chicory and blueberry) or a set of references (mushrooms). Finally, in section 5 we discuss the whole method and make some comparisons with a probabilistic approach, emphasizing their differences as well as their complementarities.

\section{Table 1.}




\section{Modelling modified atmosphere packaging (MAP)}

In MAP, oxygen and carbon dioxide partial pressures in packaging headspace evolve and settle to steady values after a transient phase until a deviation phase occurs, which marks a microbial growth or a change in the metabolic pathway of the product (close to end-life). This evolution in the internal gases partial pressures is due to the mass balance between oxygen and carbon dioxide flux through the packaging material on one hand and to the $\mathrm{O}_{2}$ and $\mathrm{CO}_{2}$ consumption/ production of the product respiration on the other hand (Figure 1). Here, gas evolution is modelled as follows:

\section{Equation 1}

$$
\dot{p}_{\mathrm{CO}_{2}}^{p k g}=\frac{P e_{\mathrm{CO}_{2}} \cdot S}{e}\left(p_{\mathrm{CO}_{2}}^{e x t}-p_{C O_{2}}^{p k g}\right)+R R_{O_{2}} \cdot m \cdot R Q=f_{2}
$$

Equation 2

With

$$
R R_{O_{2}}=\frac{R R_{O_{2} \max } \cdot p_{O_{2}}^{p k g}}{\left(K m_{a p p o_{2}}+p_{O_{2}}^{p k g}\right)}
$$

Equation 3

or

Equation 4

or

Equation 5

where the first part of the right-hand side of $f_{1}$ and $f_{2}$ describes gas flux per time unit through the packaging material, while the second part describes gas consumption (and emission) by the vegetable or fruit modelled using a Michaelis-Menten-type equation, considering no inhibition, non-competitive $\mathrm{CO}_{2}$ inhibition or uncompetitive inhibition (eq. 3, 4 or 5, respectively), that have been extensively studied (Fonseca et al., 2002). When $\mathrm{CO}_{2}$ influence is investigated on respiration, the non-competitive inhibition is preferred among the three 
equations due to its simplicity of use and good fit with most existing data concerning common products (Fishman et al., 1995; Peppelenbos and Van't Leven, 1996), nevertheless uncompetitive inhibition might be more accurate in some cases (Fonseca et al., 2002). It should be noted that for higher flexibility in MAP modelling, the combined types of inhibition might be applied as a single equation that includes all Michaelis-Menten types of inhibition as well as no inhibition (Hertog et al., 1998; Peppelenbos and Van't Leven, 1996). Table 2 summarises the different parameters, their names and units used in Eq. (1) to (5).

For a given fruit or vegetable, it is possible to experimentally determine (up to some uncertainties) oxygen and carbon dioxide partial pressures that will result in an optimal preservation. It is then possible to find optimal packaging permeabilities by using the mathematical model of eq. (1) and (2) (Charles et al., 2003) with an optimisation procedure (e.g., Levenberg-Marquard) to fit predicted partial pressures to optimal ones. Several input parameters are required for this model such as respiration rate, respiratory quotient, packaging geometry, or environment variables such as temperature. Determining exactly the values of the various parameters $(\boldsymbol{S}, \boldsymbol{e}$, , etc) involved in Eq. (1) to (5) is a difficult task. In practice, only a handful of measurements are performed and parameter values are imprecisely known, and an uncertainty analysis is necessary to ensure design robustness. Unfortunately, it is not routinely done. In the next section, we introduce an interval analysis method to do so easily on the model given by eq. (1) and (2), before presenting some case studies.

\section{Table 2.}




\section{Interval analysis and design optimisation}

Performing a probabilistic analysis on Eq. (1) and (2) and on similar dynamical models is a computationally heavy task requiring a lot of information (or making many assumptions). In contrast, interval analysis requires a minimal amount of information and, in some specific cases - such as in Eq. (1) and (2) - it may be computationally far easier to perform than probabilistic analysis.

\subsection{Basics of interval analysis}

In computational literature, interval analysis was first developed to account for numerical errors (Moore, 1979). However, interval analysis is now mostly used to perform robust analysis in applications (robotics (Jaulin et al., 2002), chemistry, biology, etc.) where the variable value is imprecisely known (Jaulin et al., 2001). In interval analysis, precise numbers are replaced by intervals, i.e. variable $\boldsymbol{x}$ is described no longer by a precise number but by an interval, with $\boldsymbol{x}^{-}$and $\boldsymbol{x}^{+}$the lowest and highest possible values of variable $\boldsymbol{x}$. describes our uncertainty about the true value of $\boldsymbol{x}$ about which we only known that it lies between $\boldsymbol{x}^{-}$and $\boldsymbol{x}^{+}$. The classical problem of interval analysis consists in replacing, in a function, the variables by intervals and to compute bounds $f([x])$ of the function such that

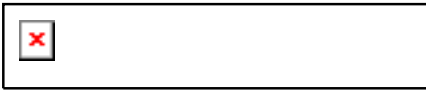
That is, the output is not a precise value but a set including all outputs obtained by choosing a precise $x \quad[x]$.

For example, if (here, $\boldsymbol{n}=\mathbf{2}$ and $\boldsymbol{m}=\mathbf{1}$ ) and $\boldsymbol{x} \in[\mathbf{2 , 5},$, , then. The two bounds $\mathbf{5}$ and $\mathbf{1 2}$ are obtained for, $\boldsymbol{y}=\mathbf{3}$ and , $\boldsymbol{y}=\mathbf{7}$, and all other possible values of $\boldsymbol{x}, \boldsymbol{y}$ give an answer between 5 and 12. We can see that, in this case, to obtain the bounds of $f([x],[y])$, we have to consider only two extreme combinations of values of $\boldsymbol{x}$ and $\boldsymbol{y}$ and no others (the single computation of the precise case is then replaced by two computations). 
In general, it will not be possible to retrieve the exact bounds of given interval uncertainty, but it may be easy to get outer approximation, and we will then speak of inclusion functions [ $\boldsymbol{f}$ ] when considering such approximations. In the previous example, is an illustrative example of inclusion function (there may be different inclusion functions, depending on the approximation method used). Among possible techniques to compute such bounds is interval arithmetic, where classical arithmetic operations $\{+, *, /,-\}$ are replaced by their interval equivalent. The quality of approximation $[\boldsymbol{f}]([\boldsymbol{x}])$ and the time to compute it both depend on the technique used and of the characteristics of the model. In our particular case, the model makes it possible to have exact bounds and efficient computations, as we shall see.

\subsection{Interval analysis to propagate uncertainties in dynamical systems}

In this paper, we are concerned with the problem of evaluating the solution of the dynamical system given by Eq. (1) and (2) combined with either Eq. (3) or Eq. (4) when parameters become interval. The computational aspect of this case has already been extensively studied in another paper (Destercke et al., 2011), and only the main assumptions are recalled here. Eq. (1) and (2) are particular instances of general systems where function describes the evolution of state variables $x$ by $\boldsymbol{m}$ ordinary differential equations (ODE's) . Here, we have two equations $f_{1}$ and $f_{2}$ describing the evolution of partial $\mathrm{O}_{2}$

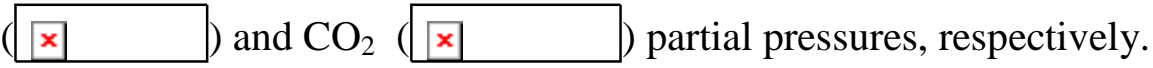

For a given time $t$, the solutions of such systems are here $\boldsymbol{m}$ values $\boldsymbol{x}_{i}(\boldsymbol{t})$. The evolutions of state variables are then obtained by solving the equations for each (discretised) time step. In the following, we denote by the time domain of the model and assume that it is discretized in a finite number of time steps. In our case, the time domain will be the life-span of the product. As in the previous section, if parameter $\boldsymbol{p}$ values become interval, the outputs $\boldsymbol{x}_{\boldsymbol{i}}(\boldsymbol{t})$ at each time step become two intervals, hence the evolutions of each variable become two 
(discretized) functions of time, a lower and an upper one, that have to be estimated. In our case, the problem is to compute the evolution of gas partial pressures, given intervals of some of the parameters given in Table 2 .

We will call a function $f_{i}$ dynamically increasing w.r.t. a parameter $\boldsymbol{p}$ or a variable $\boldsymbol{x}$ if it satisfies the following inequalities:

$\mathbf{x}$

or

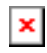

$f_{i}$ is dynamically decreasing if the inequalities are reversed (i.e., lower than or equal to zero). Normally, estimating lower and upper bounds for each variable $\boldsymbol{x}_{\boldsymbol{i}}$ and each discretized time-step $t$, i.e., to determine the lower and upper envelopes of is a difficult problem. However, if every function $f_{i}$ of is either dynamically increasing or decreasing w.r.t. each of its parameters and variables, one can concentrate only on specific extreme combinations of the interval-valued parameters and variables (initial conditions) to compute lower and upper envelopes (Delanoue, 2009; Ramdani et al., 2010; Singer and Barton, 2006), thus reducing the computations to find extrema. In such cases, one only needs to solve the system twice with usual methods (one for the upper envelope, one for the lower) for each variable. Compared to probabilistic methods, this is indeed very efficient.

Under fair assumptions (positivity of parameters of Table 2 and of $\left(\boldsymbol{p}_{\boldsymbol{O}_{2}}^{e x t}-\boldsymbol{p}_{\boldsymbol{O}_{2}}^{p k g}\right)$, negativity of $\left(\boldsymbol{p}_{\mathrm{Co}_{2}}^{\text {ext }}-\boldsymbol{p}_{\mathrm{Co}_{2}}^{p k g}\right)$, constant values of external gas partial pressures $\left.\boldsymbol{p}_{i}^{\text {ext }}\right)$, it can be shown that Eq. (1) and (2) are dynamically monotonic. Table 3 summarises those monotonicities with respect to (w.r.t.) each input parameters for function $f_{1}$ and $f_{2}$. 


\section{Table 3.}

\subsection{Parameters optimisation}

Parameter optimisation consists in searching parameters value that satisfies some objectives, i.e. to find values of some parameters $\boldsymbol{p}$ such that if they are used in function $f_{i}$ to predict $X_{i}$ (the values of the other parameters remaining the same), the prediction $\left[\boldsymbol{X}_{i}(\boldsymbol{t})\right]$ will be within or close to some specified goal $\left[\hat{x}_{i}(t)\right]$ on $X_{i}$. Here, we consider that the goal is specified as an interval over some time-domain $\hat{T} \subseteq T$ that is a subset of the whole domain. Goals are then specified as intervals $\left[\hat{\boldsymbol{x}}_{i}(t)\right]: \hat{\boldsymbol{T}} \rightarrow \mathfrak{R}$, as even optimal goals may be imprecisely known (or multiple optimal values are possible).

In our problem, the parameters to optimise are the packaging permeabilities $\mathrm{Pe}_{\mathrm{O} 2}$ to $\mathrm{O} 2$ and $\mathrm{Pe}_{\mathrm{CO}_{2}}$ to $\mathrm{CO}_{2}$. The goals $\left[\hat{\boldsymbol{x}}_{i}(\boldsymbol{t})\right]$ will be gas partial pressures $\left[\hat{p}_{\mathrm{O} 2}^{\mathrm{pkg}}(t)\right]$ and $\left[\hat{p}_{\mathrm{CO} 2}^{\mathrm{pkg}}(t)\right]$ known to provide longer shelf-life to the product. The time domain $\hat{T}$ will be restricted to the steady phase.

Note that this way of formulating an optimisation problem is not usual, even in interval analysis literature (Raïssi et al., 2004), where the goals and objective functions are usually precisely valued (e.g., correspond to precisely observed outputs). Again, such problems are in general difficult to solve, however we propose here an easy solution that again uses the monotonic properties of the system.

Consider a particular point value $\hat{\boldsymbol{p}}_{D}$ of a design parameter $p_{D}$. is said to be a guaranteed (resp. possible) solution if (resp. ) for every , given interval uncertainty on other parameters $\boldsymbol{p}$ and initial conditions $\boldsymbol{x}(\boldsymbol{0})$. A guaranteed solution is such that, despite interval uncertainties, we are certain that with the given design parameter values, the true answer lies within the goal bounds, while a possible solution is such that, with the given design parameter values, the true 
answer may or may not lie within the goal bounds. Solutions that are totally outside goal bounds are said to be non-admissible. In practice, estimating sets of guaranteed and admissible solutions can be difficult (as they are usually multivariate sets of design parameter values with complex shapes). However, it is possible with a simple procedure to provide for each design parameter $\boldsymbol{p}$ approximated evaluations of guaranteed and admissible solutions in the form of intervals $\left[\mathbf{G}_{\mathbf{p}}\right]$ and $\left[\mathbf{S}_{\mathbf{p}}\right]$, with $\left[G_{p}\right] \subseteq\left[S_{p}\right]$. An empty set means that there is currently no solution (no values of ) that could satisfy the goals. Roughly speaking, the algorithm detailed in Destercke and Guillard (2011) takes advantage of the known monotonic properties of the model to compute boundary values of $\left[\mathbf{G}_{\mathbf{p}}\right]$ and $\left[\mathbf{S}_{\mathbf{p}}\right]$. In our problem the algorithm will result in four intervals $\left[\boldsymbol{G}_{\mathrm{Pe}_{\mathrm{O}_{2}}}\right] \subseteq\left[\boldsymbol{S}_{\mathrm{Pe}_{\mathrm{O}_{2}}}\right]$ and $\left[\boldsymbol{G}_{\mathrm{Pe}_{\mathrm{CO}_{2}}}\right] \subseteq\left[\boldsymbol{S}_{\mathrm{Pe}_{\mathrm{CO}_{2}}}\right]$ proposing optimal values for the permeabilities of $\mathrm{O}_{2}$ and $\mathrm{CO}_{2}$, respectively.

The obtained sets $\left[\mathbf{G}_{\mathbf{p}}\right]$ and $\left[\mathbf{S}_{\mathbf{p}}\right]$ for each design parameter $\boldsymbol{p}$ can then be transformed into fuzzy sets (Zadeh, 1975). Indeed, while guaranteed solutions all provide the same satisfaction to the designer (they all insure that the true solution is within the goal boundaries), possible solution can be seen as having gradual satisfaction degrees for the designer, as some of them will have a more significant overlap with the goal bounds than others. First recall that a fuzzy set is a mapping from a space $\square_{x}$ to the unit interval, where is the membership degree of element $\boldsymbol{x}$. A trapezoidal fuzzy number is defined by a tuple of four numbers and is such that

\section{Equation 6}

In our case, the fuzzy set degree expresses some satisfaction degree (Dubois and Prade, 1997) provided by a parameter value w.r.t. an interval-valued objective . We propose, for , to build the trapezoidal fuzzy number such that if and otherwise. Figure 2 (see Section 4) illustrates the concept of fuzzy set. 


\subsection{Sensitivity analysis}

An uncertainty analysis usually comes with a sensitivity analysis (Helton et al., 2006) that consists in quantifying the contribution of each input parameter and variable uncertainty to the output uncertainty. It shows where uncertainty reduction would be the most beneficial to reduce output uncertainty, hence where experimental efforts should be focused. In contrast with probabilistic approaches, there are only very few works dealing with interval sensitivity analysis (Moens and Vandepitte, 2007).

In this paper, we propose to use a very simple means to perform this sensitivity analysis for a given function $f_{i}$. The details of the methodology are given in (Destercke and Guillard, 2011) and are just briefly given in the following. Let be the interval-valued output resulting from initial interval uncertainty. Then, if we denote by the length of , we define the overall imprecision of $\boldsymbol{x}_{\boldsymbol{i}}$ as

\section{Equation 8}

that is, the sum of interval lengths obtained at each time step. Now, to quantify the impact of each parameter and variable uncertainty on the output imprecision, we propose the following procedure (similar to some existing propositions in imprecise probability literature (Ferson and Tucker, 2006)): reduce, for each parameter and variable, its uncertainty by a given fraction, such a reduction coming down to transform an interval $[\boldsymbol{a}, \boldsymbol{b}]$ into an interval $\left[\boldsymbol{a}^{\prime}, \boldsymbol{b}^{\prime}\right]$ such that

\section{Equation 9}

with the middle and length of the interval, respectively.

Such a reduction gives a new interval-valued solution included in the previous one, and with an overall imprecision $x$. If is the output obtained after reducing the imprecision of parameter $\boldsymbol{p}$ by $\boldsymbol{r} \%$, the gain in the output precision generated by this reduction can then be defined as 


\section{Equation 10}

In our problem, the result of this sensitivity analysis for a particular product can be used to detect which parameters are the most responsible for the uncertainty in the gas partial pressures, eventually deciding that further experiments (or the use of more precise measurement devices) should be done on it.

\section{Application}

In this section, we apply the above framework to design Modified Atmosphere Packaging (MAP) for some fresh fruits and vegetables: chicory, mushrooms, and blueberry. The system given by Eq. (1) and (2) with either Eq. (3) to Eq. (5) are considered for modelling the respiration of produce. Numerical solving of the nonlinear ODE system (Eq. 1 to 5) was carried out using the ode45 solver of Matlab software (The Mathworks Inc., Natick, MA, USA). This routine adjusts the size of the step of time for calculations according to the importance of partial pressure variations. As $f_{1}$ and $f_{2}$ are dynamically monotonic w.r.t. each of their parameters and variables (cf. Table 3), this means that one can concentrate only on specific extreme combinations to compute lower and upper envelopes (cf. Section 3). Values of each input parameter are extracted from various references and indicated for each case study with their uncertainty. When it was not specified in literature, an uncertainty of $10 \%$ was applied on the value (it is the case for instance for the surface and the volume of the pouches, the mass of chicory, etc). Note that, in all applications, initial conditions (initial values of the two variables $\square$ and ) are considered as perfectly known (e.g. initial partial pressures are the same as in air: $21.27 \mathrm{kPa}$ for oxygen and $0 \mathrm{kPa}$ for carbon dioxide) but they also may vary $(20.62 \pm 1.21 \mathrm{kPa}$ and $0.80 \pm 0.69 \mathrm{kPa}$; Fonseca et al., 2000). Interval analysis was computed using Matlab software. 


\subsection{Case study 1: chicory}

The considered food is chicory, which has been previously studied, but without any proper uncertainty analysis (Charles et al., 2005). Chicory is usually packed in consumer-size flexible pouches (polyethylene, PE, or polypropylene, PP) containing between 0.5 and $2.0 \mathrm{~kg}$ of produce (Moras and Vernin, 2005). In this case study, $0.5 \mathrm{~kg}$ of chicory is considered packed in a 2L low density PE (LDPE) pouch with an average film thickness equal to $50 \mu \mathrm{m}$ and a total surface of $1400 \mathrm{~cm}^{2}$. Considering the dimension of packaging and the product mass, LDPE has been selected on the basis of its mass transfer properties (i.e. gas permeabilities) that should correctly match the respiration requirements of the commodity 1 (Charles et al., 2005). Storage temperature is fixed at $20^{\circ} \mathrm{C}$ and all input parameters are considered at this temperature. According to Charles et al. (2005), respiration of chicory could be modelled using Eq. 4. In Equations (1) and (2), environmental parameters subject to uncertainties are $x$ and design parameters are. Note that, when the probabilistic approach is used, no less than 9 probability distributions must be specified, and independence between variables must be consequently assumed, with some of the parameters sometimes measured only 3 times (see section 5). Note that to reach a reasonable numerical accuracy, Monte-Carlo propagation usually needs at least 100 samples, while estimating boundaries by interval analysis for $\mathrm{x}$ and requires only 4 simulations in this case.

Uncertainty propagation. Knowing the permeability of the packaging material classically used to pack chicory, the mathematical model described by Eq (1), (2), and (4) was used to simulate the evolution with time of the internal $\mathrm{O}_{2}$ and $\mathrm{CO}_{2}$ partial pressures at $20^{\circ} \mathrm{C}$.

\footnotetext{
${ }^{1}$ Note that optimal internal gas partial pressures are goals, and are not part of the models per se. They will be considered during the optimisation step
} 
Parameters with their interval uncertainty are summarised in Table 4. Maximal shelf life at $20^{\circ} \mathrm{C}$ is estimated to be 7 days (i.e. around 170 hours), therefore the simulation time domain is $\mathbf{T}=[\mathbf{0}, \mathbf{1 7 0}]$

Table 4.

The results of interval analysis are displayed in Figure 1, and at the steady states, a and . This means that, given the specified uncertainties in Table 4, the $\mathrm{O}_{2}$ and $\mathrm{CO}_{2}$ levels in the packaging can vary between their respective lower and upper curves. These curves include simulated curves obtained by Charles et al. (2005) in the same conditions without considering uncertainties (not shown in Figure 1 to preserve the readability of the graph). In the MAP experiment using the same conditions as in this simulation, and if the uncertainties were well estimated, the experimental $\mathrm{O}_{2}$ and $\mathrm{CO}_{2}$ measurements at the steady state could potentially vary between 1.6 and $8.1 \mathrm{kPa}$, and 1.9 and 5.3, respectively. Note that, due to the conservativeness of interval analysis, these ranges may be over-estimated. However, with this methodology, only four simulations where needed (two for each gas) to estimate the bounds, and no unverified assumption (e.g., independence of all variables) has been made. It also provides worst cases referring to the lowest $\mathrm{O}_{2}$ and highest $\mathrm{CO}_{2}$ contents that are determinant to anticipate risks of anoxia and $\mathrm{CO}_{2}$ phytotoxicity, respectively. Those two critical points are main causes of failure in MAP design marked by the development of off-flavour and off-odour as well as discoloration of the commodity. In the case of chicory, the interval analysis ensures that the recommended storage atmosphere is within the modelled interval during a shelf life of 7 days $\left(3-4 \% \mathrm{O}_{2}\right.$ and $4-5 \% \mathrm{CO}_{2}$ according to Mannapperuma et al. (1989), and that neither anoxia $\left(\mathrm{O}_{2}\right.$ lower than $\left.1 \%\right)$ nor excessive $\mathrm{CO}_{2}$ content (higher than 10\%) would occur even during the transient period (Van de Velde and 
Hendrickx, 2001; Vanstreels et al., 2002). This kind of certainty is very helpful to guarantee no detrimental deviation in produce quality.

\section{Figure 1.}

Optimisation step. When the best oxygen and carbon dioxide permeabilities suiting a particular fruit or vegetable are not known a priori, the MAP model, Eq. (1), (2), and (4), is used to perform a reverse engineering task. In this case, optimal oxygen and carbon dioxide concentrations in the modified atmosphere packaging have to be known and specified. Then, an identification step of the optimal permeabilities can be run by taking into account the parameters uncertainty (specified in Table 4) of every environmental parameter. To ensure that optimal $\mathrm{O}_{2}$ and $\mathrm{CO}_{2}$ concentrations (the goals) were considered for the steady state and not for the transient phase, we have taken $x$ and the time domain was maintained at around 7 days $\mathbf{T}=[\mathbf{0}, \mathbf{1 7 0}]$. The optimal concentrations at the steady state were fixed as $x \quad$ and for every, according to previous work (Charles et al. 2005) since oxygen partial pressure has to be between 2 and $10 \%$ and carbon dioxide partial pressure between 2 and $5 \%$ at the steady state. Levenberg-Marquardt Algorithm (Nocedal and Wright, 1999) was used to identify the optimal permeabilities. Figures $2 \mathrm{~A} \& 2 \mathrm{~B}$ show the range of $\mathrm{O}_{2}$ and $\mathrm{CO}_{2}$ permeabilities obtained. There are some guaranteed solutions, that all provide the same satisfaction degree to the designer (reaching the maximal value 1 in Figures $2 \mathrm{~A} \& 2 \mathrm{~B}$ ). These solutions will all insure that the true solution is within the goal boundaries, $\hat{\boldsymbol{p}}_{o_{2}}^{\text {pkg }}$ and . There are some possible solutions that can be seen as having gradual satisfaction degrees (between 0 and 1 on the fuzzy set in Figures $2 \mathrm{~A} \& 2 \mathrm{~B}$ ) for the designer, as some of them will have a more significant overlap with the goal bounds than others. According to Figures 2A \& 2B, guaranteed solutions, ranged from 1.04 to $1.59 \times 10^{-15} \mathrm{~mol} \cdot \mathrm{m}^{-1} \cdot \mathrm{s}^{-1} \cdot \mathrm{Pa}^{-1}$ and 4.39 to 
$6.28 \times 10^{-15} \mathrm{~mol} \cdot \mathrm{m}^{-1} \cdot \mathrm{s}^{-1} \cdot \mathrm{Pa}^{-1}$ for respectively $\mathrm{O}_{2}$ and $\mathrm{CO}_{2}$ permeability. Possible, but not guaranteed solutions, $\mathrm{x}$, ranged from 0.27 to $5.11 \times 10^{-15} \mathrm{~mol} \cdot \mathrm{m}^{-1} \cdot \mathrm{s}^{-1} \cdot \mathrm{Pa}^{-1}$ and 1.09 to $23.68 \times 10^{-15} \mathrm{~mol} \cdot \mathrm{m}^{-}{ }^{1} \cdot \mathrm{s}^{-1} \cdot \mathrm{Pa}^{-1}$. Figure 3 shows the result of the interval analysis done with optimal parameters belonging to and the resulting oxygen and carbon dioxide partial pressures lie well within the objectives. It is obvious from the fuzzy sets of Figures $2 \mathrm{~A} \& 2 \mathrm{~B}$ that, with a $10 \%$ variation, the $\mathrm{O}_{2}$ and $\mathrm{CO}_{2}$ permeabilities of LDPE chosen for generating uncertainty propagation does not fully meet the guaranteed solution. With a higher precision during assessment of mass transfer properties, this material could be part of guaranteed solution.

\section{Figure 2.}

\section{Figure 3.}

Sensitivity analysis. Table 5 summarises the sensitivity analysis performed according to the method previously presented. For each variable $\otimes$ and, we have evaluated the gain in uncertainty after an imprecision reduction of $50 \%$ of each (environmental and design) parameter. The last row $(A l l)$ indicates the gain in the output precision when all parameters uncertainty is reduced by $50 \%$.

The results indicate, among other things, that uncertainties of packaging permeabilities have the highest impact on gas internal partial pressure: while $\mathrm{O}_{2}$ permeability uncertainty has an important impact on both $\mathrm{O}_{2}$ and $\mathrm{CO}_{2}$ internal partial pressure (the reduction resulting in a gain of about $10 \%$ for each), $\mathrm{CO}_{2}$ permeability uncertainty only impacts the $\mathrm{CO}_{2}$ internal pressure, and has almost no effects on $\mathrm{O}_{2}$ internal pressure. The great influence of surface and thickness uncertainties on gas internal partial pressures was not surprising since they are part of the equation of gas permeation through the packaging material, with permeability values. 
The effect of was more important on $\mathrm{O}_{2}$ content than $\mathrm{CO}_{2}$. As expected, the uncertainty of the respiration quotient $(\boldsymbol{R} Q)$ only impact on the $\mathrm{CO}_{2}$ internal pressure, while uncertainty, due to the large value of , has no impact on the resulting uncertainty for both variables. It is worth noting that cumulating all the gains obtained following a reduction of $50 \%$ on all input parameters uncertainty, more than $50 \%$ of precision could be gained on $\mathrm{O}_{2}$ and $\mathrm{CO}_{2}$ internal partial pressure!

\section{Table 5.}

\subsection{Case study 2: mushrooms}

Contrary to the previous case study (chicory) where all the parameters and their uncertainty came from a single work, the case of mushrooms is a bit more complicated since several scientific publications dealing with respiration parameters of mushrooms are available. While its respiration pathway can be considered in its simple formalism (MickaëlisMenten type with no $\mathrm{CO}_{2}$ inhibition), various values of respiration parameters for common mushrooms (Agaricus biporus L) are provided, as shown in Table 1. The large difference in respiration rate is mainly due to the considered strain, flush and stage of maturity, but also to the method of determination used. In order to take into account this physiological variability in the prediction of $\mathrm{O}_{2}$ and $\mathrm{CO}_{2}$ partial pressure $(x$ and $)$ at equilibrium in the packaging of mushrooms, these multiple sources were taken into account to define a range of probable for mushrooms. This range was considered as input parameters in the model (Eq. (1), (2) and (3)) (Table 6). Mushrooms are usually placed in punnets, which are then wrapped into plastic pouches. A possible packaging material commercially available is, for example, stretchable PVC film (Guillaume et al., 2010; Lopez Briones et al., 1993). The system considered in this study was a mass of $250 \mathrm{~g}$ of mushrooms wrapped with a stretchable PVC film of 11 microns of thickness (Guillaume et al., 2010), considering a total volume of $1.0 \mathrm{~L}$ and $676 \mathrm{~cm}^{2}$ of total 
surface area (http://www.champignons-paris.com/). All the characteristics of the mushrooms / packaging system used in the simulation are described in Table 6 and considered at $20^{\circ} \mathrm{C}$.

\section{Table 6.}

Uncertainty propagation. Knowing the $\mathrm{O}_{2}$ and $\mathrm{CO}_{2}$ permeabilities of the stretchable PVC film (Table 6), the mathematical model (Eq. (1), (2) and (3)) was used to simulate the evolution with time of $\mathrm{O}_{2}$ and $\mathrm{CO}_{2}$ internal partial pressure. An interval analysis was used to assess the impact of input parameters uncertainty on the prediction. The targeted shelf life of fresh mushrooms at $20^{\circ} \mathrm{C}$ is 5 days at the very most; the time domain for simulation was then h. The results of interval analysis are displayed in Figure 4. At the steady states the $\mathrm{O}_{2}$ and $\mathrm{CO}_{2}$ partial pressure ranges are $\mathrm{a}$ and . Using this classical PVC film for packing mushrooms, anoxia is reached in the packaging in less than $10 \mathrm{~h}$ when considering all uncertainties on input parameters and the largest upper and lower limit for maximal respiration rate () taken from the different sources found on this food product. This might induce a turn into fermentative catabolism responsible for off-flavours and off-odours in most fresh produce; but the case of mushrooms is quite peculiar. Some authors demonstrated that their respiration rate remained constant whatever the $\mathrm{O}_{2}$ level, even around $0.2 \mathrm{kPa}$, with a respiratory quotient equal to unit (Lopez Briones et al., 1992; Varoquaux et al., 1999). They also determined a negligible $\quad x \quad$ value $(<0.1 \mathrm{kPa})$ that has been considered in the present work for modelling purpose. Considering this literature, mushroom catabolism is supposed to be aerobic until $0.2 \mathrm{kPa}$. Then the anoxic condition of $0.2-0.3 \mathrm{kPa}$, identified upon modelling, would not be detrimental to this fresh commodity. However, it may cause safety issues by favouring growth of Clostridium botulinum, moreover when it is combined with high $\mathrm{CO}_{2}$ content (Gonzalez-Fandos et al., 2000). While the lowest limit for maximal 
respiration rate led to $\mathrm{CO}_{2}$ partial pressures equal to or lower than $5 \mathrm{kPa}$ within the time domain defined, the highest limit for maximal respiration rate displayed $\mathrm{CO}_{2}$ partial pressures higher than $5 \mathrm{kPa}$ and even more than $10 \mathrm{kPa}$ during the transient period. The threshold value of $5 \mathrm{kPa}$ has been previously determined at $10^{\circ} \mathrm{C}$ as an initiator of mushroom discolouration such as yellowing (Lopez Briones et al., 1992). Based on these simulations and interval analysis, this packaging material did not match the gas permeabilities requirement necessary for mushrooms. Hopefully, in real conditions of use, mechanical stretching of PVC may alter its barrier properties by increasing both $\mathrm{O}_{2}$ and $\mathrm{CO}_{2}$ permeabilities (Guillaume et al., 2010; Trommer and Morgenstern, 2009).

\section{Figure 4.}

Optimisation step. The next step was to identify the $\mathrm{O}_{2}$ and $\mathrm{CO}_{2}$ permeabilities that are best suited to the packing of mushrooms and to evaluate the impact of parameters uncertainty on the reliability of the prediction using interval analysis. Eq (1), (2) and (3) were used to perform a reverse engineering task as described for chicory. For mushrooms, literature gave some optimal $\mathrm{O}_{2}$ and $\mathrm{CO}_{2}$ concentrations for the storage of mushrooms at $20^{\circ} \mathrm{C}$ which are

respectively $\quad$ and for the steady state period (Lopez Briones et al., 1992). Identification of and that best suit mushrooms was then performed by taking into account uncertainties on input parameters reported in Table 6. In this condition, no guaranteed packaging solutions could be found that best suited the requirements of mushrooms as illustrated in Figures 5A \& 5B. Figure 6 illustrates well that the upper and lower envelops for the $\mathrm{O}_{2}$ and $\mathrm{CO}_{2}$ internal partial pressures lay beyond the targeted ranges for these two gases following the uncertainty propagation during the optimisation step. 


\section{Figure 5.}

Figure 6.

Sensitivity analysis. In order to identify the parameter(s) and its(their) uncertainty(ies) that impact the prediction the most, a sensitivity analysis was performed. As for case 1, the gain in uncertainty was evaluated after applying an imprecision reduction of $50 \%$ for each variable successively. The results are given in Table 7 . The results of Table 7 indicated that among all parameters uncertainty has the most important impact on $\mathrm{O}_{2}$ internal partial pressure (the reduction of $50 \%$ applied on uncertainty resulted in a gain of more than $50 \%$ on the precision of $\mathrm{O}_{2}$ partial pressure prediction) while packaging permeabilities, and, have the greatest impact on $\mathrm{CO}_{2}$ partial pressure prediction (reduction of uncertainty of around $20 \%$ ) followed by $\boldsymbol{R} \boldsymbol{Q}$ (reduction of uncertainty of around 10\%). This result was expected. Indeed, mushrooms are characterized by a high biological variability and then the reproducibility of the measure of respiration parameters is touchy. That's why a large range of variations was noticed for between the different sources (Table 6). This sensitivity analysis illustrated well that an accurate experimental determination of the respiration parameters (especially when is not influent as we considered herein) could be crucial to provide reliable predictions of internal gas partial pressure. Contrary to $\mathrm{O}_{2}$ partial pressure, $\mathrm{CO}_{2}$ partial pressure was more dependent on $\boldsymbol{R} \boldsymbol{Q}$ which appears logical because in Eq. (2), was directly calculated from and $\boldsymbol{R Q}$. It is worth noticing that, as for chicory, cumulating all the gains obtained following a reduction of $50 \%$ on all input parameters uncertainty, more than $50 \%$ of precision could be gained on $\mathrm{O}_{2}$ and $\mathrm{CO}_{2}$ internal partial pressure (even more than $60 \%$ for $\mathrm{O}_{2}$ )!

Both the optimisation step and sensitivity analysis clearly demonstrate the importance of having a good knowledge on physiological behaviour and precise input parameters with low uncertainty for prediction concerns. Up to now the state of the art on common white mushroom respiration and storage is still too controversial to foresee accurate prediction and 
guaranteed packaging solutions. For instance respiration of mushrooms might be considered following a Michaëlis-Menten-type equation with no inhibition (Cliffe-Byrnes and O' Beirne, 2007; Varoquaux et al., 1999) or uncompetitive (Cliffe-Byrnes and O' Beirne, 2007; Iqbal et al., 2009b), and the Michaëlis-Menten constant, $\mathbf{x}$, as negligible (Cliffe-Byrnes and O' Beirne, 2007; Varoquaux et al., 1999) or not (Iqbal et al., 2009). While the effect of a high amount of $\mathrm{CO}_{2}$ seems to be detrimental to their whiteness whatever the source, the decrease in $\mathrm{O}_{2}$ content might exhibit almost no effect either on their respiration (Varoquaux et al., 1999) or quality attributes (Lopez Briones et al., 1992; Lopez Briones et al., 1993), or it might slow down their respiration (Iqbal et al., 2009) as well as delay their development as cap opening, veil breaking, stem elongating (Roy et al., 1995). Such differences are mainly attributed to the material used. Most often, the complete identification of common white mushrooms is not mentioned but it is obvious that strain, number of flush and development stage should be considered to improve the knowledge on their physiological behaviour and reduce uncertainties on physiological parameters. This would lead to more reliable simulations and maybe possible guaranteed packaging solutions.

\section{Table 7.}

\subsection{Case study 3: blueberry}

A third vegetal product was chosen, 'Duke' blueberry, which is characterized in the model by a significant uncompetitive $\mathrm{CO}_{2}$ inhibition (significant value of ). Small berries such as blueberries are commonly packaged and sold to consumers in vented petroleum-based clamshell containers or pouches. In this study, $200 \mathrm{~g}$ of blueberries were considered packed in a $0.6 \mathrm{~L}$ LDPE pouch with a surface area of $690 \mathrm{~cm}^{2}$ as in the study of Song, Vorsa et al (2002). According to Song et al. (2002), respiration of blueberries could be modelled using 
Eq. 5 describing uncompetitive inhibition. All input parameters required in Eqs. (1), (2) and (5) are given in Table 8 and considered at $25^{\circ} \mathrm{C}$.

\section{Table 8.}

Uncertainty propagation. To perform the simulation, the shelf life of blueberries was considered as 5 days at $25^{\circ} \mathrm{C}$. The simulated curves (not shown) obtained taking into account uncertainty propagation during MAP simulation are in agreement with the experimental and predicted ones determined by Song et al. (2002) at two temperatures (15 and 25 degrees C). However, these authors did not study the effect of error propagation in their simulation studies. By considering the uncertainties of all input parameters, the $\mathrm{O}_{2}$ partial pressure at equilibrium may potentially vary between 0.3 and $10 \%, \mathrm{x}$, and $\mathrm{CO}_{2}$ between 3 and $6 \%, \mathrm{x}$. These upper and lower bounds for $\mathrm{O}_{2}$ and $\mathrm{CO}_{2}$ are equivalent to a $10^{\circ} \mathrm{C}$ variation (from 25 to 15 degrees C) as observed by Song et al. (2002)!

According to Beaudry et al. (1992), who worked on MAP of 'Highbush' blueberries at various temperatures, minimal $\mathrm{O}_{2}$ partial pressure at equilibrium should be at $4 \mathrm{kPa}$ at $25{ }^{\circ} \mathrm{C}$ to avoid a turn into fermentative metabolism. Assuming that 'Duke' blueberries may tolerate the same level of $\mathrm{O}_{2}$ and considering the uncertainty propagation, the chosen LDPE package could induce off-flavours and off-odours, since the lower $\mathrm{O}_{2}$ limit was found at $0.2 \mathrm{kPa}$.

Optimisation step. Results previously obtained point out the fact that by using an LDPE pouch, if $\mathrm{O}_{2}$ partial pressure is significantly reduced in the packaging (below $10 \%$ ), $\mathrm{CO}_{2}$ is moderately increased (the upper limit for $\mathrm{CO}_{2}$ is only $5 \%$ ). In general, berries have prolonged postharvest shelf life when exposed to levels of $\mathrm{CO}_{2}$ above 15\% (Almenar et al., 2007; Beaudry, 1993; Beaudry et al., 1992) (Beaudry, Cameron et al. 1992; Beaudry 1993; 
Almenar, Del-Valle et al. 2007). The packaging material commercially used for blueberries is thus not satisfactory. An identification of the packaging permeabilities suitable to reach optimal $\mathrm{O}_{2}$ and $\mathrm{CO}_{2}$ concentration favourable to the conservation of blueberries was then performed. For this purpose, it is necessary to first define the range of targeted $\mathrm{O}_{2}$ and $\mathrm{CO}_{2}$ concentrations suitable for MAP of blueberries. For $\mathrm{O}_{2}$, several authors (Kim et al., 1995; Rosenfeld et al., 1999) claim less-than-or-equals $9 \% \mathrm{O}_{2}$ as the optimum amount. We can thus consider that has to be focused on $9 \%$ with a reasonable range of variation between 8 and $10 \%$.

Different $\mathrm{CO}_{2}$ optimal concentrations have been reported to prolong blueberry shelf life. While several authors (Kim et al., 1995; Rosenfeld et al., 1999) claim between 15\% and 18\% $\mathrm{CO}_{2}$ as the optimum amount, Harb and Streif (2004) reported that 'Duke' blueberries react to increased $\mathrm{CO}_{2}$ amounts $(>12 \%)$ with loss of firmness and acidity content and a negative impact on flavour. $\mathrm{CO}_{2}$ is not only a respiration inhibitor but also an antifungal compound. Its effect is dependent on concentration, exposure time and application time following fruit harvest. Therefore high levels of $\mathrm{CO}_{2}$ are usually required in MAP of blueberries to delay fungi growth and prolong shelf life. As regards this antifungal effect, Harb and Streif (2004) also reports that a minimal amount of $6 \% \mathrm{CO}_{2}$ is needed to retard $B$. cinerea (one of the main spoilage moulds) growth in blueberries stored near 0 degree C. In absence of a clear consensus for optimal $\mathrm{CO}_{2}$ concentration in MAP of blueberries, we will thus consider in this study that may vary between 6 and $15 \%$ at equilibrium.

By using these optimal partial pressures and the parameters listed in Table 8, the window of optimal permeabilities suitable for maintaining blueberry quality at $25^{\circ} \mathrm{C}$ during 5 days were identified. While no guaranteed solutions were found for $\mathrm{O}_{2}$ permeability, a range of guaranteed solutions was identified for $\mathrm{CO}_{2}$ (between 1.20 to $1.59 \times 10^{-15} \mathrm{~mol} \cdot \mathrm{m}^{-1} \cdot \mathrm{s}^{-1} \cdot \mathrm{Pa}^{-1}$ ). That means that by using a packaging material having a $\mathrm{CO}_{2}$ permeability in this range, and in 
the conditions used for this simulation (geometry, mass of blueberries, uncertainty on input parameters given in Table 8, etc.), we are sure, even in the worst case, to reach the targeted $\mathrm{CO}_{2}$ range of 6-15\% at equilibrium in the packaging (upper and lower $\mathrm{CO}_{2}$ simulated curves lay between 7 and 14\%). On the contrary, $\mathrm{O}_{2}$ curves lay between 4 and 13\% (curves not shown). In this case, only possible solutions could have been identified, ranging from 0.76 to $2.89 \times 10^{-15} \mathrm{~mol} \cdot \mathrm{m}^{-1} \cdot \mathrm{s}^{-1} \cdot \mathrm{Pa}^{-1}$. It is important to point out that even if these solutions are only possible but not guaranteed solutions, the $\mathrm{O}_{2}$ concentrations reached in the headspace at equilibrium will never drop below $4 \mathrm{kPa}$, which is satisfactory from the vegetable/fruit point of view. This impossibility to identify a set of guaranteed solutions for $\mathrm{O}_{2}$ permeabilities could be explained by the fact that the targeted $\mathrm{O}_{2}$ range is narrow, and given the uncertainties of input parameters and the conservative interval analysis used here, the possible range of $\mathrm{O}_{2}$ concentrations at equilibrium is large.

Sensitivity analysis. Table 9 summarises the sensitivity analysis performed on the blueberry case study. The results indicate that both packaging and respiration parameters impact the precision on $\mathrm{x}$ and. The uncertainty has the most important impact on $\mathrm{O}_{2}$ and $\mathrm{CO}_{2}$ internal partial pressures uncertainty (50\% reduction on uncertainty results in a gain of around $10 \%$ on $x$ and ), followed by and uncertainties, which impact in the same manner (around 8-9\%) $\mathrm{O}_{2}$ and $\mathrm{CO}_{2}$ internal pressures. Surprisingly, uncertainty has a very low impact on $\square$ and precisions. Indeed, it was expected that this parameter uncertainty could significantly impact the prediction because of its importance in the modelling of blueberries respiration (uncompetitive inhibition). It seems that uncertainty is more impacting than that of or even .

Table 9. 


\section{Discussion}

In this paper we propose interval analysis as a useful alternative to probabilistic analysis that requires far less information in order to give reliable results. Interval analysis results are easy to compute when functions satisfy certain monotonicity properties, as is the case for functions used in MAP modelling. We have used this method for two purposes: (1) classical uncertainty analysis during MAP modelling, including propagation (prediction of $\mathrm{O}_{2}$ and $\mathrm{CO}_{2}$ internal partial pressures) and sensitivity analysis (quantification of input uncertainty impact on output uncertainty), and (2) robust design under uncertainties (identification of $\mathrm{O}_{2}$ and $\mathrm{CO}_{2}$ permeabilities that are best suited to a targeted product). The approach is applied to three case studies: chicory, mushrooms and blueberries, chosen for their differences. Chicory displays moderate maximal respiration rate, while mushrooms are characterised by a high respiration rate. Blueberries display moderate maximal respiration rate and a significant $\mathrm{CO}_{2}$ inhibition whereas this inhibition is negligible for chicory and mushrooms. For chicory and blueberries, uncertainties indicated in the reference where used in the interval analysis (or, if it is not precise, an uncertainty of $10 \%$ was applied). For mushrooms, respiration parameters come from different references that yield to a larger variation range for those parameters (especially). It was thus interesting to study this case.

\section{Biological variability and interval analysis}

A first remark is that guaranteed solutions for permeabilities seldom occur (for which we are sure that the $\mathrm{O}_{2}$ and $\mathrm{CO}_{2}$ internal pressures will lay in optimal range of the product). This is due to the combination of interval analysis conservativeness and of the important biological variability of fresh fruits and vegetables. Multiplicity of references (such as for mushroom 
respiration parameters) makes the problem even worse. Also, optimal ranges may be too narrow to find guaranteed solutions (blueberry case). However, interval analysis is able to handle all these cases (even when dealing with very heterogeneous sources, as was the case for mushrooms) in a straightforward but conservative way. It is also important to recall that guaranteed solutions are very robust solutions, and that possible solutions that were obtained in all cases may be sufficient for a given application. The analysis has also stressed some important facts, such as the need to clearly identify the upper and lower bounds of the equilibrium atmosphere for the product concerned and to deepen the knowledge of the behaviour of fresh fruits and vegetables at those bounds.

Sensitivity analysis has shown in all cases that a reduction of $50 \%$ on each parameter uncertainty enables to gain a precision on the predicted $\mathrm{O}_{2} / \mathrm{CO}_{2}$ internal partial pressure of around $50 \%$ and even more than $60 \%$ for mushrooms (for ). Results have shown that $x$ uncertainty has an important impact if its value is high (mushrooms and blueberries), while its impact is lower if $\square$ value is low (chicory), and in this case the uncertainty on packaging parameters (permeabilities, thickness, surface, etc.) impact more on $\square$ and $\square$ uncertainties. Surprisingly, even if a $\mathrm{CO}_{2}$ inhibition is significant and cannot be neglected in respiration modelling (case of blueberries), has a low impact on $x$ and $\square$ precision. The final conclusion from these first studies is that experimental efforts must be carried out on the determination of accurate values, and then, on packaging characteristics $(\times, \times, \boldsymbol{x}, \boldsymbol{e})$. However, it should be kept in mind that the performed sensitivity analysis of this paper, apart from the conclusions mentioned above, are largely illustrative. Indeed, sensitivity analysis is a useful tool to detect which parameters have the most impact on the output precision of a mathematical model, but it makes sense only if it is performed to achieve certain goals (i.e. to know on what parameter experiments or technological innovation should focus, given certain time, technical or cost constraints). For instance, in MAP modelling for chicory, it appears 
difficult to gain precision on the thickness since it is inherent to the constraints of shaping processes. Conversely, in the case of mushrooms, uncertainties on respiration rate could be reduced by focusing on specific strains (limiting the population of interest) or by improving and standardizing the methods used to assess this parameter since each of the methods used had some limitations (Fonseca et al., 2002).

\section{Interval analysis versus Monte Carlo probabilistic method}

We now compare interval analysis to Monte Carlo probabilistic method for the three cases. To perform Monte Carlo simulation and ensure sufficient accuracy, $\mathrm{m}=2000$ data were randomly drawn between the bounds of their respective uncertainty (see Tables 4, 6 and 8) using a procedure already used by Pénicaud et al. (2010). As the distribution of each input variable is not known a priori and could not be experimentally determined (less than 5 determinations for each parameter), a uniform distribution was considered. The generation of these virtual parameters was carried out on Matlab software (The Mathworks, Inc., Natick, MA, USA) using a routine function (rand.m). For each set of virtual parameters generated, either a MAP modelling or an optimisation step was performed.

Considering uncertainty propagation by using $\mathrm{MC}$ simulations during the simulation of internal $\mathrm{O}_{2}$ and $\mathrm{CO}_{2}$ partial pressures, intervals of possible values (with bounds taken as the 95\% confidence interval) at the steady state are, for the three cases, narrower than those obtained with interval analysis, which is in agreement with the theory (i.e., that all MC simulations are within the interval analysis bounds). For example, $\mathrm{O}_{2}$ may vary between

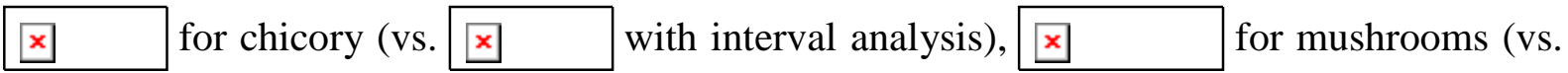

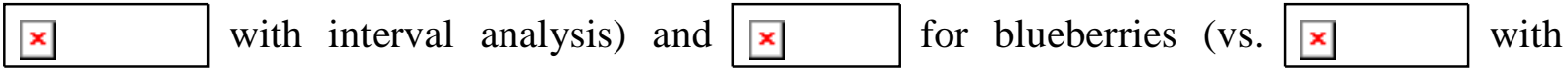
interval analysis). Indeed, Monte-Carlo analysis corresponds to choosing a particular distribution within the bounds, as well as independence between the variables, while interval 
analysis corresponds to a "worst" and "best" case analysis (for instance, there are no averaging or counterbalancing effects with interval analysis, as can happen with MC analysis).

Concerning the optimisation steps, MC simulations provided distributions of optimal values for $x$ and $x$. We represented these results as histograms, probability densities and fuzzy sets assuming value 1 for the mean optimal value and bounded by the $95 \%$ confidence interval of the MC simulation (see Figures 2C \& 2D and Figures 5C \& 5D for chicory and mushrooms respectively). Two facts can be noticed: MC analysis usually provide sharper and more informative distributions (allowing one to build confidence intervals), and although the two analyses roughly agree on the range of optimal values, they sometimes point to different best options. Indeed, while for chicory interval analysis proposes a best $\mathrm{O}_{2}$ permeability between 1 and $1.5 \times 10^{-15} \mathrm{~mol} \cdot \mathrm{m}^{-1} \cdot \mathrm{s}^{-1} \cdot \mathrm{Pa}^{-1}$, probabilistic analysis recommends a value around $2.5 \mathrm{~mol} \cdot \mathrm{m}^{-1} \cdot \mathrm{s}^{-1} \cdot \mathrm{Pa}^{-1}$. In this case, guaranteed solutions of interval analysis should be preferred, as they do not make any unsupported hypothesis. The same happens for mushrooms and $\mathrm{CO}_{2}$ permeability, however in this case interval analysis is unable to provide guaranteed solutions, and "best" solutions proposed by the probabilistic analysis (around $11 \times 10^{-15} \mathrm{~mol} \cdot \mathrm{m}^{-1} \cdot \mathrm{s}^{-1} \cdot \mathrm{Pa}^{-1}$ ) are not discarded by interval analysis, and could be considered as a potential alternative.

In practice, industry may be satisfied with designs that prolong the shelf life of a given percentage of products (for instance, $95 \%$ or $99 \%$ of the products remaining edible may be enough), particularly if it saves important costs. It should be noted that interval analysis does not provide such information (only providing bounds and no statistical information), while probabilistic analysis does. However the reliability of the more detailed information provided by a probabilistic analysis may be questioned when only little data or information is available. In practice, the two methods can be seen as two extreme solutions to handle uncertainty: interval analysis needs a minimal amount of information and gives a poorly informative but 
robust result, while proper probabilistic analysis requires a great amount of information and gives a very informative result whose reliability may be questioned if unverified assumptions had to be made. In practice, the real state of available information will be in the middle: more than simple bounds, but not enough to estimate reliable probability distributions.

Hence, rather than being opposed, the two methods should be seen as complementary: interval analysis can be performed as a first quick and robust analysis, and a subsequent probabilistic analysis can be used to refine prediction. Any disagreement between their conclusions (such as $\mathrm{O}_{2}$ permeability for chicory) can then be detected and investigated more closely. Another solution is to consider imprecise probabilistic theories. Indeed, such theories are more flexible and can model information states that cannot be adequately handled by intervals or probability distributions. However while such models combine the advantages of each method (robustness and statistical estimation), they also (partially) share their respective drawbacks (higher computational cost and tendency to give large uncertainty bounds).

\section{Conclusion}

In this paper, we have used interval analysis to study the impact of uncertainty propagation during MAP modelling and during a design optimisation step (using MAP models in a reverse manner) to quickly produces optimal values for $\mathrm{O}_{2}$ and $\mathrm{CO}_{2}$ permeabilities. This design optimisation step takes account of interval uncertainty and can cope with imprecisely specified goals (range of targeted $\mathrm{O}_{2}$ and $\mathrm{CO}_{2}$ internal partial pressure), distinguishing between possible solutions (potentially satisfying the targeted $\mathrm{O}_{2} / \mathrm{CO}_{2}$ concentrations) and guaranteed solutions (certainly satisfying the goal). The difference between the two kinds of solutions is represented by the means of fuzzy sets describing optimal solutions. We have also proposed an easy method to perform some first sensitivity analyses. 
Methodological perspectives to this work include the development of more precise methods, eventually ending up with more accurate and multi-dimensional approximations of the sets $[\mathrm{G}]$ and $[\mathrm{S}]$ of guaranteed and possible answers. Also, it may be desirable to extend the current approach to hybrid uncertainty models mixing interval and probabilistic uncertainty, as information concerning different parameters may vary in quantity and quality. However, these two perspectives would involve more computationally demanding procedures, thus reducing the number of models one could work with. More applied perspectives include the combination of the optimisation system with a decision support system where a user can search a database for optimal packaging (fuzzy sets describing sets of optimal solutions would then be used as user preferences).

\section{Acknowledgements}

The authors gratefully acknowledge the ANR (ANR-07-PNRA-029) for its financial support to the development of the Tailorpack website. 


\section{References}

Almenar, E., Del-Valle, V., Hernández-Muñoz, P., Lagarón, J.M., R., C., Gavara, R., 2007. Equilibrium modified atmosphere packaging of wild strawberries. J. Sci. Food Agric. 87, 1931-1939.

Barron, C., Varoquaux, P., Guilbert, S., Gontard, N., Gouble, B., 2002. Modified atmosphere packaging of cultivated mushroom (Agaricus bisporus L.) with hydrophilic films. J. Food Sci. 67, 251-255.

Baudrit, C., Helias, A., Perrot, N., 2007. Uncertainty analysis in food engineering involving imprecision and randomness. 5th International Symposium on Imprecise Probability: Theories and Applications, Prague, Czech Republic

Baudrit, C., Helias, A., Perrot, N., 2009. Joint treatment of imprecision and variability in food engineering: Application to cheese mass loss during ripening. J. Food Eng. 3, 284-292.

Beaudry, R.M., 1993. Effect of carbon dioxide partial pressure on blueberry fruit respiration and respiratory quotient. Postharvest Biol. Technol. 3, 249 - 258.

Beaudry, R.M., Cameron, A.C., Shirazi, A., Dostal-Lange, D.L., 1992. Modified atmosphere packaging of blueberry fruit: effect of temperature on package $\mathrm{O} 2$ and $\mathrm{CO} 2$. J. Am. Soc. Hortic. Sci. 117, 436-441.

Bedford, T., Cooke, R., 2001. Probabilistic Risk Analysis. Foundations and Methods. Cambridge University Press, Cambridge, UK.

Charles, F., Sanchez, J., Gontard, N., 2003. Active modified atmosphere packaging of fresh fruits and vegetables: Modeling with tomatoes and oxygen absorber. J. Food Sci. 68, 1736-1742.

Charles, F., Sanchez, J., Gontard, N., 2005. Modeling of active modified atmosphere packaging of endives exposed to several postharvest temperatures. J. Food Sci. 70, E443E449.

Cliffe-Byrnes, V., O' Beirne, D., 2007. Effects of gas atmosphere and temperature on the respiration rates of whole and sliced mushrooms (Agaricus bisporus) - Implications for film permeability in modified atmosphere packages. J. Food Sci. 72, E197-E204.

Delanoue, N., 2009. A new method for integrating ode based on monotonicity, SWIM 09 (A small workshop on Interval Methods).

Destercke, S., Buche, P., Guillard, V., 2011. A flexible bipolar querying approach with imprecise data and guaranteed results. Fuzzy Set Syst. 169, 51 - 64.

Destercke, S., Guillard, V., 2011. Interval analysis on non-linear monotone systems as an efficient tool to optimise fresh food packaging. Comput. Electron. Agr. 79: 116-124

Dubois, D., Prade, H., 1997. The three semantics of fuzzy sets. Fuzzy Set Syst. 90, 141 150.

Ferson, S., Ginzburg, L.R., 1996. Different methods are needed to propagate ignorance and variability. Reliab. Eng. Syst. Safe. 54, 133-144.

Ferson, S., Troy Tucker, W., 2006. Sensitivity analysis using probability bounding Reliab. Eng. Syst. Safe. 91, 1435 - 1442.

Fishman, S., Rodov, V., Peretz, J., Benyehoshua, S., 1995. Model for gas exchange dynamics in modified atmosphere packages of fruits and vegetables. J. Food Sci. 60, 10781083.

Floros, J.D., Matsos, K.I., 2005. Introduction to modified atmosphere packaging, In: Han, J. (Ed.), Innovations in food packaging. Elsevier academic press, New York, USA, pp. 159172. 
Fonseca, S.C., Oliveira, F.A.R., Brecht, J.K., 2002. Modelling respiration rate of fresh fruits and vegetables for modified atmosphere packages: a review. J. Food Eng. 52, 99-119.

Gonzalez-Fandos, E., Gimenez, M., Olarte, C., Sanz, S., Simon, A., 2000. Effect of packaging conditions on the growth of micro-organisms and the quality characteristics of fresh mushrooms (Agaricus bisporus) stored at inadequate temperatures. J. Appl. Microbiol. 89, 624-632.

Guillaume, C., Schwab, I., Gastaldi, E., Gontard, N., 2010. Biobased packaging for improving preservation of fresh common mushrooms (Agaricus bisporus L.). Innov. Food Sci. \& Emerg. Technol. 11, 690-696.

Harb, J., Streif, J., 2004. Controlled atmosphere storage of highbush blueberries cv. 'Duke'. Eur. J. Hort. Sci. 69, 66-72.

Helton, J., Johnson, J., Oberkampf, W., Sallaberry, C., 2006. Sensitivity analysis in conjunction with evidence theory representations of epistemic uncertainty. Reliab. Eng. Syst. Safe. 91, 1414-1434.

Hertog, M., Peppelenbos, H.W., Evelo, R.G., Tijskens, L.M.M. 1998. A dynamic and generic model of gas exchange of respiring produce: the effects of oxygen, carbon dioxide and temperature. Postharvest Biol. Technol. 14, 335-349

Hertog, M., Lammertyn, J., Desmet, M., Scheerlinck, N., Nicolai, B.M., 2004. The impact of biological variation on postharvest behaviour of tomato fruit. Postharvest Biol. Technol. 34, 271-284.

Hertog, M., Lammertyn, J., Scheerlinck, N., Nicolai, B.M., 2007a. The impact of biological variation on postharvest behaviour: The case of dynamic temperature conditions. Postharvest Biol. Technol. 43, 183-192.

Hertog, M., Scheerlinck, N., Lammertyn, J., Nicolai, B.M., 2007b. The impact of biological variation on postharvest behaviour of Belgian endive: The case of multiple stochastic variables. Postharvest Biol. Technol. 43, 78-88.

Hertog, M., Scheerlinck, N., Nicolai, B.M., 2009. Monte Carlo evaluation of biological variation: Random generation of correlated non-Gaussian model parameters. J. Comput. Appl. Math. 223, 1-14.

Iqbal, T., Rodrigues, F.A.S., Mahajan, P.V., Kerry, J.P., 2009a. Effect of Time, Temperature, and Slicing on Respiration Rate of Mushrooms. J. Food Sci. 74, E298-E303.

Iqbal, T., Rodrigues, F.A.S., Mahajan, P.V., Kerry, J.P., 2009b. Mathematical modelling of $\mathrm{O}-2$ consumption and $\mathrm{CO} 2$ production rates of whole mushrooms accounting for the effect of temperature and gas composition. Int. J. Food Sci. Technol. 44, 1408-1414.

Jaulin, L., Kieffer, M., Didrit, O., Walter, E., 2001. Applied Interval Analysis, London.

Jaulin, L., Kieffer, M., Walter, E., Meizel, D., 2002. Guaranteed robust nonlinear estimation with application to robot localization. IEEE Trans. on Syst., Man and Cybern. C32, 374-381.

Kim, H.K., Song, Y.S., Yam, K.L., 1995. Influence of modified atmosphere on quality attributes of blueberry. Food Biotechnol. 113-116.

Lopez Briones, G., Varoquaux, P., Bureau, G., Pascat, B., 1993. Modified atmosphere packaging of common mushroom. Int. J. Food Sci. Technol. 28, 57-68.

Lopez Briones, G., Varoquaux, P., Chambroy, Y., Bouquant, J., Bureau, G., Pascat, B., 1992. Storage of common mushroom under controlled atmospheres. Int. J. Food Sci. Technol. 27, 493-505.

Mahajan, P.V., Oliveira, F.A.R., Montanez, J.C., Frias, J., 2007. Development of userfriendly software for design of modified atmosphere packaging for fresh and fresh-cut produce. Innov. Food Sci. \& Emerg. Technol. 8, 84-92. 
Mannapperuma, J., Zagory, D., Singh, R.P., Kader, A.A., 1989. Design of polymeric packages for modified atmosphere storage of fresh produce, Fifth international controlled atmosphere research conference, Wenatchee, W. A.

Moens, D., Vandepitte, D., 2007. Interval sensitivity theory and its application to frequency response envelope analysis of uncertain structures. Comput. Methods Appl. Mech. Eng. 196, 2486 - 2496.

Moore, R., 1979. Methods and applications of Interval Analysis, SIAM Studies in Applied Mathematics. SIAM, Philadelphia.

Moras, X., Vernin, X., 2005. Le préemballage des légumes et des fraises (Hortipratic), In: CTIFL (Ed.). Lavoisier.

Nocedal, J., Wright, S., 1999. Numerical Optimization. Springer, New York.

Pénicaud, C., Peyron, S., Guillard, V., Bohuon, P. \& Gontard, N. 2010. Ascorbic acid infood: development of a rapid analysis technique and application to diffusivity determination. Food Research International 43: 838-847

Peppelenbos, H.W., Van't Leven, J., 1996. Evaluation of four types of inhibition for modelling the influence of carbon dioxide on oxygen consumption of fruits and vegetables. Postharvest Biol. Technol. 7, 27-40.

Raïssi, T., Ramdani, N., Candau, Y., 2004. Set membership state and parameter estimation for systems described by nonlinear differential equations. Automatica 40, 1771 - 1777.

Ramdani, N., Meslem, N., Candau, Y., 2010. Computing reachable sets for uncertain nonlinear monotone systems. Nonlinear Analysis: Hybrid Systems 4, 263 - 278.

Rosenfeld, H.J., Meberg, K.R., Haffner, K., Sundell, H.A., 1999. MAP of highbush blueberries: sensory quality in relation to storage temperature, film type and initial high oxygen atmosphere. Postharvest Biol. Technol. 16, 27-36.

Roy, S., Anantheswaran, R.C., Beelman, R.B., 1995. Fresh mushroom quality as affected by modified atmosphere packaging. J. Food Sci. 60, 334-340.

Singer, A.B., Barton, P.I., 2006. Bounding the solutions of parameter dependent nonlinear ordinary differential equations. SIAM J. Sci. Comput. 27, 2167-2182.

Song, Y., Vorsa, N., Yam, K.L., 2002. Modeling respiration-transpiration in a modified atmosphere packaging system containing blueberry. J. Food Eng. 53, 103-109.

Trommer, K., Morgenstern, B., 2009. Nonrigid Microporous PVC Sheets: Preparation and Properties. J. Appl. Polym. Sci. 115, 2119-2126.

Van de Velde, M.D., Hendrickx, M.E., 2001. Influence of storage atmosphere and temperature on quality evolution of cut Belgian endives. J. Food Sci. 66, 1212-1218.

Vanstreels, E., Lammertyn, J., Verlinden, B.E., Gillis, N., Schenk, A., Nicolai, B.M., 2002. Red discoloration of chicory under controlled atmosphere conditions. Postharvest Biol. Technol. 26, 313-322.

Varoquaux, P., Gouble, B., Barron, C., Yildiz, F., 1999. Respiratory parameters and sugar catabolism of mushroom (Agaricus bisporus Lange). Postharvest Biol. Technol. 16, 51-61.

Zadeh, L., 1975. The concept of a linguistic variable and its application to approximate reasoning-i. Inform. Sciences 8, 199-249. 


\section{Figures captions}

Figure 1: Uncertainty propagation during the modelling of modified atmosphere packaging in the case of chicory (case I) packed in LDPE pouches (simulation carried out at $20^{\circ} \mathrm{C}$ with parameters listed in Table 4)

Figure 2: Optimal $\mathrm{O}_{2}\left(\mathrm{~A}\right.$ and $\mathrm{C}$ ) and $\mathrm{CO}_{2}(\mathrm{~B}$ and $\mathrm{D})$ permeability range for case I: chicory. Results of interval analysis (guaranteed and possible solutions) are on the left and of Monte Carlo simulation on the right (histograms, densities and fuzzy sets centred on mean value and with support equal to $95 \%$ confidence interval)

Figure 3: Uncertainty propagation during identification step of optimal $\mathrm{O}_{2}$ and $\mathrm{CO}_{2}$ permeabilities in the case of chicory (case I)

Figure 4: Uncertainty propagation during the modelling of modified atmosphere packaging in the case of mushrooms (case II) packed in plastic tray (simulation carried out at $20^{\circ} \mathrm{C}$ with parameters listed in Table 6)

Figure 5: Optimal $\mathrm{O}_{2}$ (A and $\mathrm{C}$ ) and $\mathrm{CO}_{2}(\mathrm{~B}$ and D) permeability range for case II: mushrooms. Results of interval analysis (guaranteed and possible solutions) are on the left and of Monte Carlo simulation on the right (histograms, densities and fuzzy sets centred on mean value and with support equal to $95 \%$ confidence interval)

Figure 6: Uncertainty propagation during identification step of optimal $\mathrm{O}_{2}$ and $\mathrm{CO}_{2}$ permeabilities in the case of mushrooms (case II) 


\section{Figure 1.}

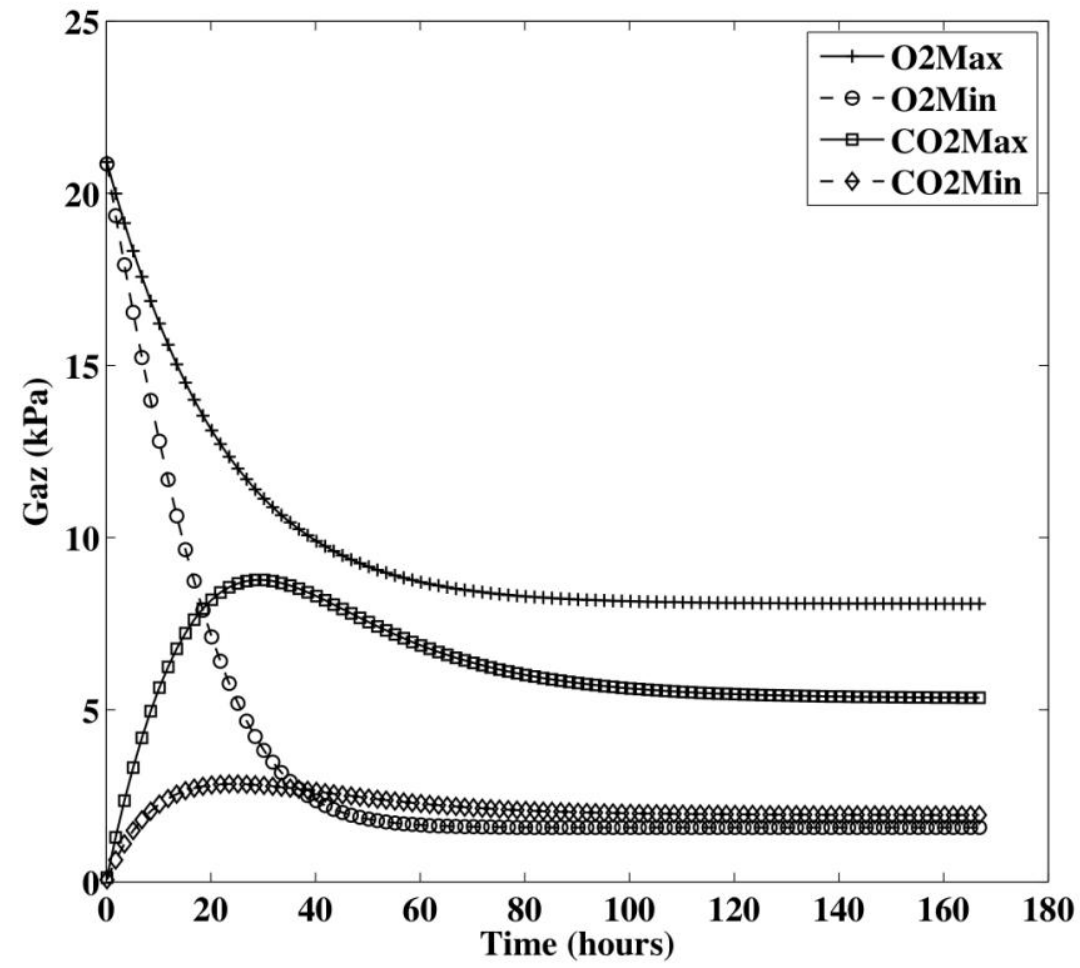

Figure 1: Uncertainty propagation during the modelling of modified atmosphere packaging in the case of chicory (case I) packed in LDPE pouches (simulation carried out at $20^{\circ} \mathrm{C}$ with parameters listed in Table 4) 


\section{Figure 2.}

(A)

(C)

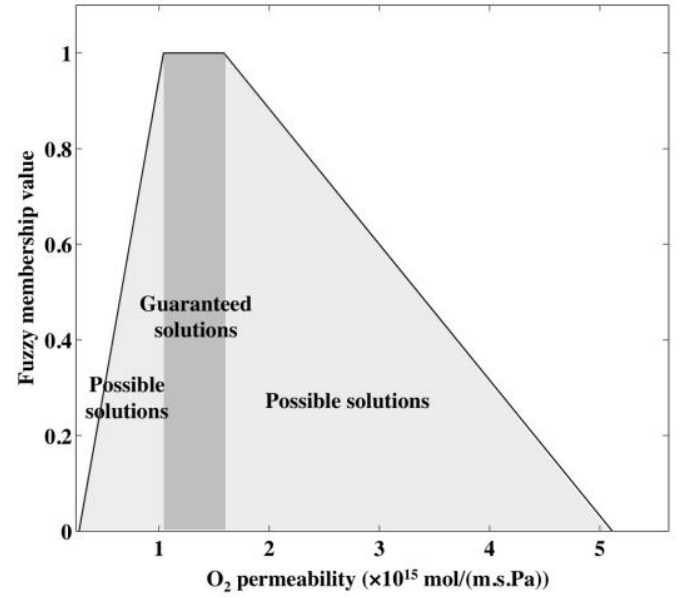

(B)

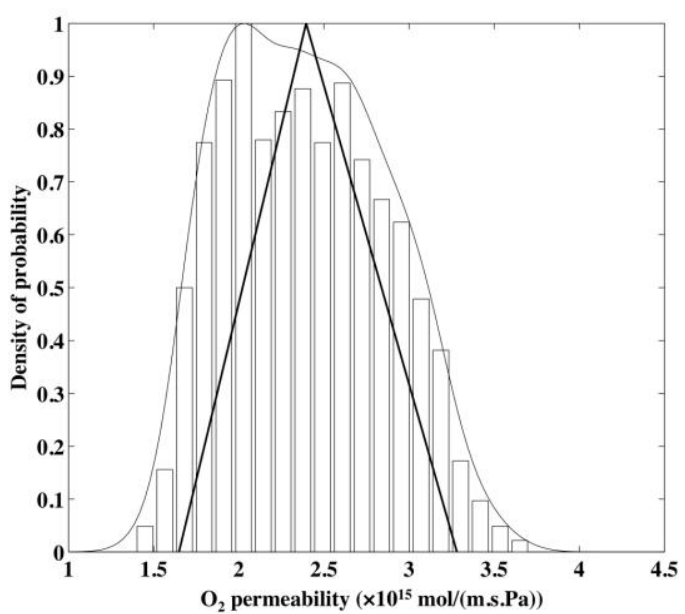

(D)

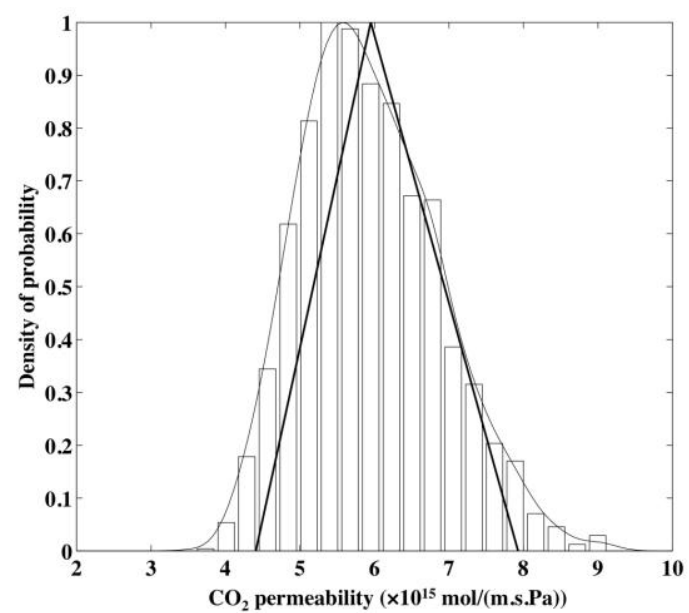

Figure 2: Optimal $\mathrm{O}_{2}(\mathrm{~A}$ and $\mathrm{C})$ and $\mathrm{CO}_{2}(\mathrm{~B}$ and $\mathrm{D})$ permeability range for case I: chicory. Results of interval analysis (guaranteed and possible solutions) are on the left and of Monte Carlo simulation on the right (histograms, densities and fuzzy sets centred on mean value and with support equal to $95 \%$ confidence interval) 


\section{Figure 3.}

Figure 3: Uncertainty propagation during identification step of optimal $\mathrm{O}_{2}$ and $\mathrm{CO}_{2}$ permeabilities in the case of chicory (case I) 


\section{Figure 4.}

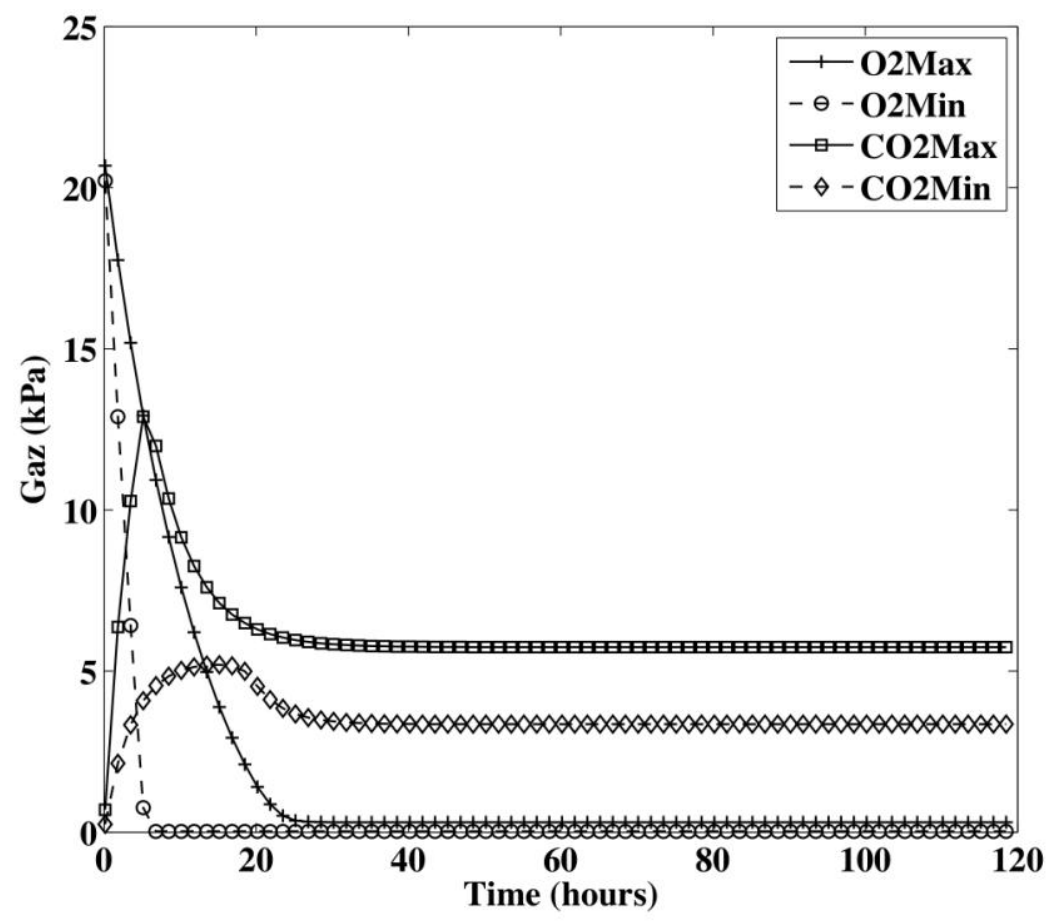

Figure 4: Uncertainty propagation during the modelling of modified atmosphere packaging in the case of mushrooms (case II) packed in plastic tray (simulation carried out at $20^{\circ} \mathrm{C}$ with parameters listed in Table 6) 


\section{Figure 5.}

(A)

(C)

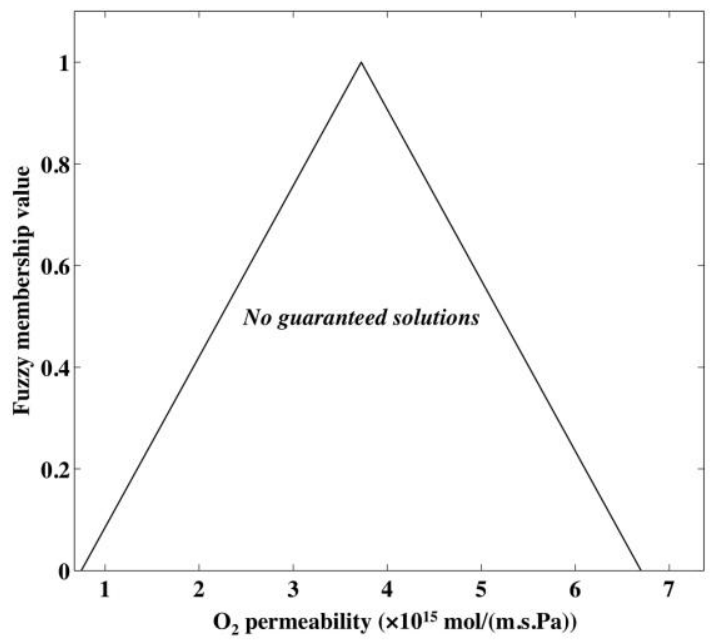

(B)

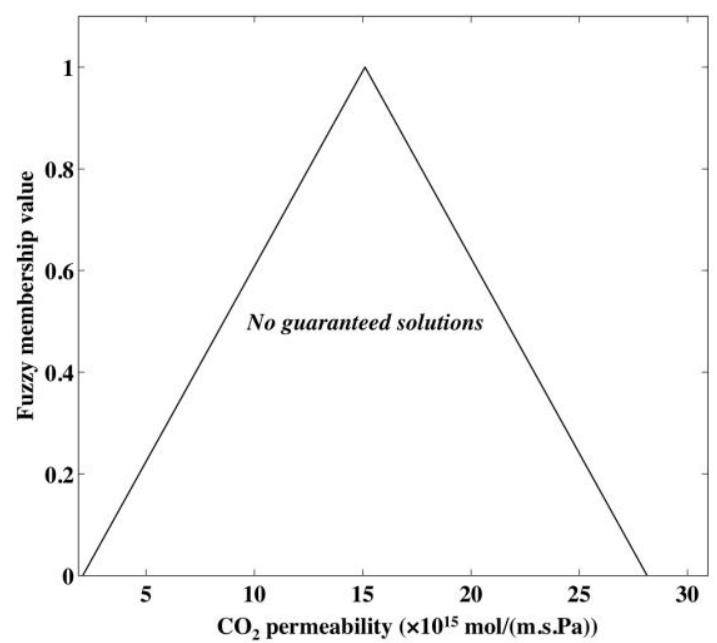

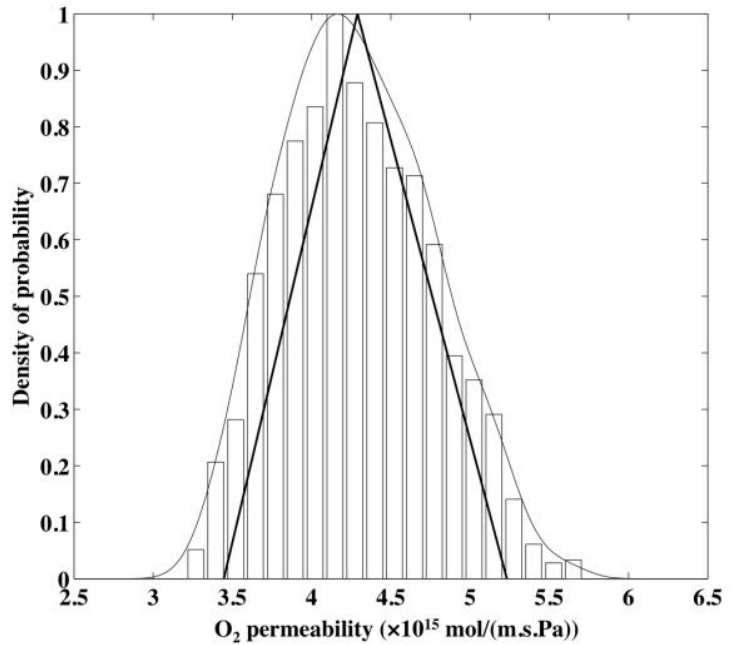

(D)

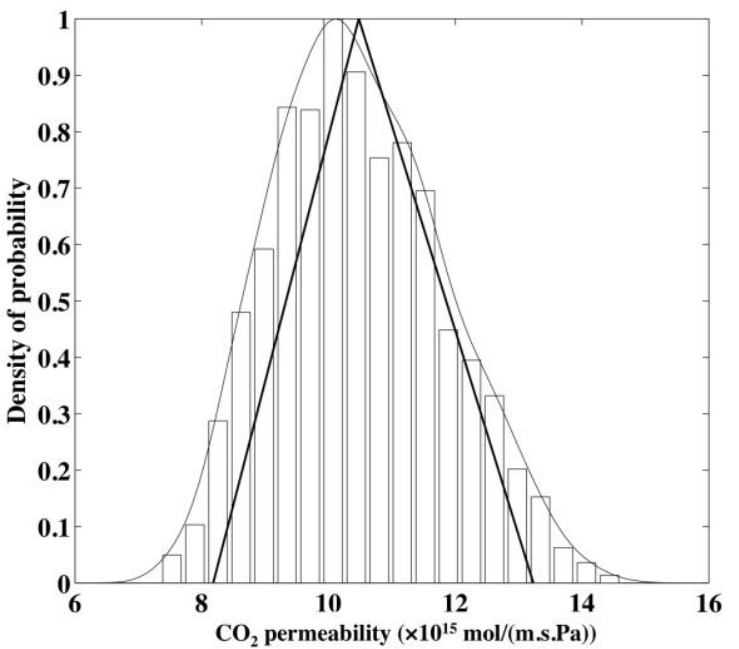

Figure 5: Optimal $\mathrm{O}_{2}(\mathrm{~A}$ and $\mathrm{C})$ and $\mathrm{CO}_{2}(\mathrm{~B}$ and $\mathrm{D})$ permeability range for case II: mushrooms. Results of interval analysis (guaranteed and possible solutions) are on the left and of Monte Carlo simulation on the right (histograms, densities and fuzzy sets centred on mean value and with support equal to $95 \%$ confidence interval). 


\section{Figure 6.}

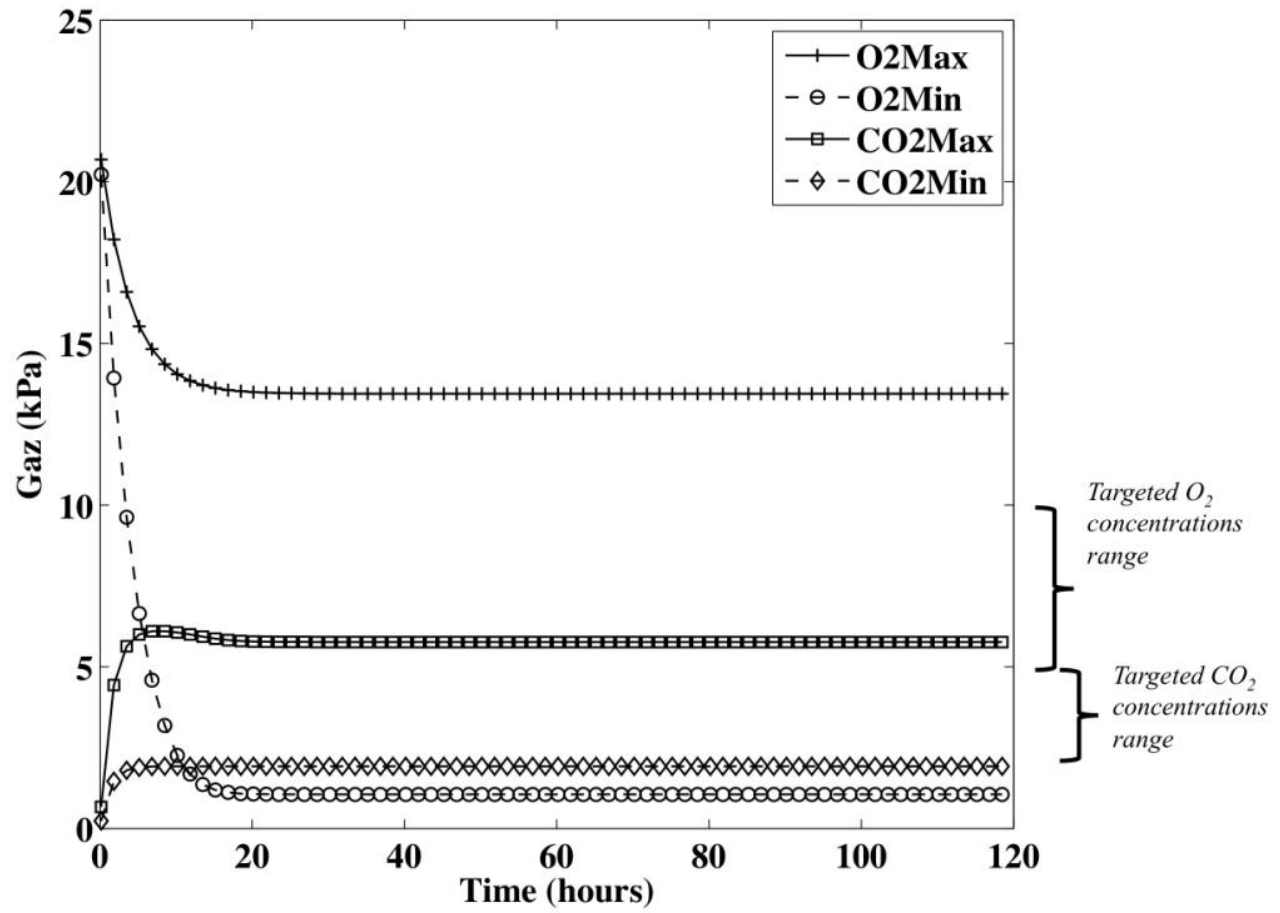

Figure 6: Uncertainty propagation during identification step of optimal $\mathrm{O}_{2}$ and $\mathrm{CO}_{2}$ permeabilities in the case of mushrooms (case II) 


\section{List of tables}

Table 1: Range of values for respiration parameters of Agaricus biporus $L$. found in the scientific literature

Table 2: Parameters of food/packaging system

Table 3: Monotonicity of each function $f_{1}$ and $f_{2}$ with respect to input parameters

Table4: Values of input parameters $(a t) 0^{\circ} \mathrm{C}$ ) and their respective uncertainty for the uncertainty propagation step (case 1: chicory) from Charles et al. (2005)

Table 5: Results of sensitivity analysis after a reduction $r=50 \%$ (case I: chicory)

Table 6: Values of input parameters $\left(\mathrm{at}^{\circ} \mathrm{o}^{\circ} \mathrm{C}\right)$ and their respective uncertainty for the case of mushrooms

Table 7: Effect of $50 \%$ of decrease on input parameter uncertainty on the reliability of internal partial pressure obtained at equilibrium in the case of mushrooms

Table 8: Values of input parameters $\left(\right.$ at $25^{\circ} \mathrm{C}$ ) and their respective uncertainty for the uncertainty propagation step (case 3: blueberry) from (Song et al. 2002)

Table 9: Effect of 50\% of decrease on input parameter uncertainty on the reliability of internal partial pressure obtained at equilibrium in the case of blueberries 
Table 1: Range of values for respiration parameters of Agaricus biporus $L$. found in the scientific literature

\begin{tabular}{|c|c|c|c|c|c|c|}
\hline Reference & Type of model & $\begin{array}{l}\text { Temperature } \\
\left({ }^{\circ} \mathrm{C}\right)\end{array}$ & $\mathrm{mmol} \mathrm{O}_{2} \cdot \mathrm{kg}^{-1} \cdot \mathrm{h}^{-1}$ & $\mathbf{k P a}$ & $\mathbf{k P a}$ & $\begin{array}{l}R Q \\
(-)\end{array}$ \\
\hline $\begin{array}{l}\text { (Lopez Briones et al., } \\
\text { 1992) }\end{array}$ & No inhibition & 10 & $2.34(-)$ & $(-)$ & $(-)$ & $(-)$ \\
\hline \multirow{2}{*}{$\begin{array}{l}\text { (Varoquaux et al., } \\
\text { 1999) }\end{array}$} & \multirow{2}{*}{ No inhibition } & 10 & 1.82 & \multirow{2}{*}{$<0.1$} & \multirow{2}{*}{$(-)$} & \multirow{2}{*}{0.78} \\
\hline & & 20 & 5.27 & & & \\
\hline \multirow{2}{*}{ (Barron et al., 2002) } & \multirow{2}{*}{ No inhibition } & 10 & $2.0(-)$ & $(-)$ & \multirow{2}{*}{$(-)$} & \multirow{2}{*}{$(-)$} \\
\hline & & 20 & $6.0(-)$ & $(-)$ & & \\
\hline \multirow{2}{*}{$\begin{array}{l}\text { (Cliffe-Byrnes and 0' } \\
\text { Beirne, 2007) }\end{array}$} & \multirow{2}{*}{ No inhibition } & 10 & $1.50(-)$ & 1.03 & \multirow{2}{*}{$(-)$} & 0.76 \\
\hline & & 16 & $2.90(-)$ & 0.93 & & 0.81 \\
\hline \multirow{2}{*}{ (Iqbal et al., 2009a) } & \multirow{2}{*}{ No inhibition } & 12 & $3.05 \pm 0.14$ & \multirow{2}{*}{$(-)$} & \multirow{2}{*}{$(-)$} & \multirow{2}{*}{$0.89 \pm 0.19$} \\
\hline & & 20 & $6.04 \pm 0.34$ & & & \\
\hline (Iqbal et al., 2009b) & $\begin{array}{c}\text { Uncompetitive } \\
\text { inhibition }\end{array}$ & 10 & $2.84 \pm 0.05$ & $4.1 \pm 0.3$ & $39.1 \pm 5.1$ & $0.86(-)$ \\
\hline
\end{tabular}


Table 2: Parameters of food/packaging system

\begin{tabular}{|c|c|c|}
\hline Parameter & Name & Units \\
\hline & $\mathrm{O}_{2}$ permeability & mol.m $\mathrm{m}^{-1} \cdot \mathrm{s}^{-1} \cdot \mathrm{Pa}^{-1}$ \\
\hline & $\mathrm{CO}_{2}$ permeability & mol.m ${ }^{-1} \cdot \mathrm{s}^{-1} \cdot \mathrm{Pa}^{-1}$ \\
\hline$S$ & Packaging surface & $\mathrm{m}^{2}$ \\
\hline \multirow[t]{6}{*}{$e$} & Packaging thickness & $\mathrm{m}$ \\
\hline & Partial pressure of $\mathrm{j}$ in $\mathrm{i}$ & $\mathrm{kPa}$ \\
\hline & $\mathrm{O}_{2}$ respiration rate & mmol.kg-1 ${ }^{-1}$ \\
\hline & Max. $\mathrm{O}_{2}$ respiration rate & mmol.kg-1. $\mathrm{h}^{-1}$ \\
\hline & Mickaëlis-Menten constant & $\mathrm{kPa}$ \\
\hline & $\mathrm{CO}_{2}$ non-comp. inhibition & $\mathrm{kPa}$ \\
\hline$x$ & $\begin{array}{l}\text { constant } \\
\mathrm{CO}_{2} \text { uncomp. inhibition } \\
\text { constant }\end{array}$ & $\mathrm{kPa}$ \\
\hline$m$ & Mass of food & $\mathrm{kg}$ \\
\hline$R Q$ & Respiration quotient & $(-)$ \\
\hline
\end{tabular}


Table 3: Monotonicity of each function $f_{1}$ and $f_{2}$ with respect to input parameters

\begin{tabular}{|c|c|c|}
\hline Parameter & $f_{1}$ & $f_{2}$ \\
\hline & $\pi$ & N.A. \\
\hline & N.A. & $y$ \\
\hline$S$ & $\pi$ & ע \\
\hline \multirow[t]{6}{*}{$e$} & $y$ & $\pi$ \\
\hline & $\mathbf{y}$ & $y$ \\
\hline & $y$ & $\pi$ \\
\hline & $\mathbf{y}$ & $\pi$ \\
\hline & त & $y$ \\
\hline & & $\pi$ \\
\hline$m$ & $\mathbf{y}$ & $\pi$ \\
\hline$R Q$ & N.A. & $\pi$ \\
\hline
\end{tabular}


Table 4: Values of input parameters $\left(a t 20^{\circ} \mathrm{C}\right.$ ) and their respective uncertainty for the uncertainty propagation step (case 1: chicory) from Charles et al. (2005)

\begin{tabular}{l|c} 
Parameter & Uncertainty \\
\hline & {$[878-1278] \times 10^{-18}$} \\
& {$[3614-4634] \times 10^{-18}$} \\
$\boldsymbol{S}$ & {$[12-16] \times 10^{-2}$} \\
$\boldsymbol{V}$ & {$[0.0018-0.0022]$} \\
$\boldsymbol{e}$ & {$[4-6] \times 10^{-5}$} \\
\hline $\mathbf{x}$ & {$[1.3-1.5]$} \\
\hline $\mathbf{x}$ & {$[8.26-10.26]$} \\
\hline $\boldsymbol{x}$ & {$[1025-2025] \times 10^{3}$} \\
$\boldsymbol{m} \boldsymbol{R}$ & {$[0.45-0.55]$} \\
& {$[0.67-0.81]$}
\end{tabular}


Table 5: Results of sensitivity analysis after a reduction $r=50 \%$ (case I: chicory)

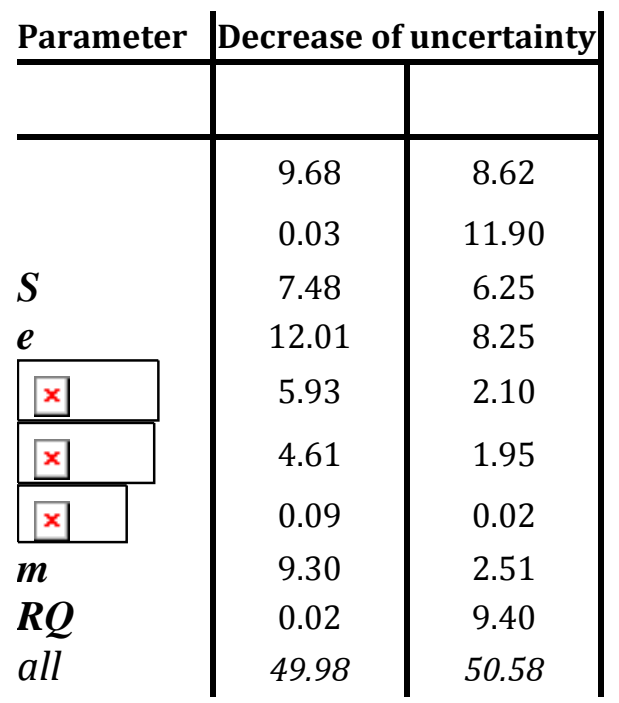


Table 6: Values of input parameters $\left(\right.$ at $20^{\circ} \mathrm{C}$ ) and their respective uncertainty for the case of mushrooms

\begin{tabular}{|c|c|c|}
\hline Parameter & Uncertainty & Reference \\
\hline & {$[740-904] \times 10^{-18}$} & (Guillaume et al. 2010) \\
\hline & {$[2938-3590] \times 10^{-18}$} & (Guillaume et al. 2010) \\
\hline$S$ & {$[0.061-0.074]$} & http://www.champignons-paris.com/ \\
\hline $\boldsymbol{V}$ & {$[9.50-11.6] \times 10^{-4}$} & http://www.champignons-paris.com/ \\
\hline $\boldsymbol{e}$ & {$[10.9-11.1] \times 10^{-6}$} & (Guillaume et al. 2010) \\
\hline$x$ & {$[2.90-6.04]$} & (Varoquaux et al. 1999; Barron et al. 2002; \\
\hline$x$ & {$[0.1]^{*}$} & (Varoquaux et al. 1999) \\
\hline$m$ & {$[0.240-0.275]$} & http://www.champignons-paris.com/ \\
\hline$R Q$ & {$[0.78-0.89]$} & $\begin{array}{l}\text { (Cliffe-Byrnes and O' Beirne 2007; Iqbal et al. } \\
\text { 2009b) }\end{array}$ \\
\hline
\end{tabular}

*from Varoquaux et al. $1999,<0.1$ and due to sensitivity of experimental devices, this parameter cannot be determined more precisely and was considered as a fixed value. 
Table 7: Effect of $50 \%$ of decrease on input parameter uncertainty on the reliability of internal partial pressure obtained at equilibrium in the case of mushrooms

\begin{tabular}{l|c|c|} 
Parameter & \multicolumn{2}{|c|}{ Decrease of uncertainty } \\
\hline & & \\
\hline & 6.77 & 15.07 \\
& 0.57 & 17.92 \\
$\boldsymbol{S}$ & 6.15 & 2.11 \\
$\boldsymbol{e}$ & 0.68 & 0.20 \\
\hline $\mathbf{\nabla}$ & 50.10 & 3.35 \\
\hline $\mathbf{⿴}$ & 0 & 0 \\
$\mathbf{m}$ & 11.51 & 0.34 \\
$\boldsymbol{R} \boldsymbol{Q}$ & 0.47 & 11.90 \\
all & 63.07 & 50.77
\end{tabular}


Table 8: Values of input parameters $\left(a t 25^{\circ} \mathrm{C}\right.$ ) and their respective uncertainty for the uncertainty propagation step (case 3: blueberry) from (Song et al. 2002)

\begin{tabular}{l|c} 
Parameter & Uncertainty \\
\hline & {$[1395-1481] \times 10^{-18}$} \\
& {$[4284-4529] \times 10^{-18}$} \\
$\boldsymbol{S}$ & {$[0.0621-0.0759]$} \\
$\boldsymbol{V}$ & {$[622.8-761.2] \times 10^{-6}$} \\
$\boldsymbol{e}$ & {$[29.70-37.29] \times 10^{-6}$} \\
$\boldsymbol{R} \boldsymbol{R}_{\mathrm{O}_{2} \max }$ & {$[1.134-1.386]$} \\
$\boldsymbol{K} \boldsymbol{m}_{\text {appO }}$ & {$[0.109-0.133]$} \\
$\boldsymbol{K i}_{\text {co }_{2}}^{u}$ & {$[15.18-18.55]$} \\
$\boldsymbol{m}$ & {$[0.19-0.21]$} \\
$\boldsymbol{R} \boldsymbol{Q}$ & {$[0.67-0.82]$}
\end{tabular}


Table 9: Effect of $50 \%$ of decrease on input parameter uncertainty on the reliability of internal partial pressure obtained at equilibrium in the case of blueberries

\begin{tabular}{l|c|c|} 
Parameter & \multicolumn{2}{|c|}{ Decrease of uncertainty } \\
\hline & $\boldsymbol{p}_{\boldsymbol{o}_{2}}^{\text {pkg }}$ & \\
\hline & 2.34 & 1.16 \\
& 0.37 & 3.12 \\
$\boldsymbol{S}$ & 6.61 & 7.94 \\
$\boldsymbol{e}$ & 7.97 & 8.84 \\
$\boldsymbol{R} \boldsymbol{R}_{\mathrm{O}_{\text {max }}}$ & 9.43 & 8.11 \\
$\boldsymbol{K}_{\text {appo }_{2}}$ & 0.24 & 0.24 \\
$\boldsymbol{K} \boldsymbol{j}_{\text {co }_{2}}$ & 1.55 & 1.40 \\
$\boldsymbol{m}$ & 5.06 & 4.00 \\
$\boldsymbol{R} \boldsymbol{Q}$ & 1.51 & 11.50 \\
all & 43.30 & 48.49
\end{tabular}

